\title{
OPEN Decoupling the metal insulator transition and crystal field effects of $\mathrm{VO}_{2}$
}

\author{
In-Hui Hwang ${ }^{1,2}$, Chang-In Park ${ }^{1}$, Sunmog Yeo ${ }^{3}$, Cheng-Jun Sun ${ }^{2} \&$ Sang-Wook Han ${ }^{1 凶}$
}

$\mathrm{VO}_{2}$ is a highly correlated electron system which has a metal-to-insulator transition (MIT) with a dramatic change of conductivity accompanied by a first-order structural phase transition (SPT) near room temperature. The origin of the MIT is still controversial and there is ongoing debate over whether an SPT induces the MIT and whether the $T_{c}$ can be engineered using artificial parameters. We examined the electrical and local structural properties of $\mathrm{Cr}$ - and $\mathrm{Co}$-ion implanted $\mathrm{VO}_{2}\left(\mathrm{Cr}^{-} \mathrm{VO}_{2}\right.$ and Co- $\mathrm{VO}_{2}$ ) films using temperature-dependent resistance and $\mathrm{X}$-ray absorption fine structure (XAFS) measurements at the $\mathrm{V} \mathrm{K}$ edge. The temperature-dependent electrical resistance measurements of both $\mathrm{Cr}-\mathrm{VO}_{2}$ and $\mathrm{Co}-\mathrm{VO}_{2}$ films showed sharp MIT features. The $\mathrm{T}_{\mathrm{c}}$ values of the $\mathrm{Cr}-\mathrm{VO}_{2}$ and $\mathrm{Co}-\mathrm{VO}_{2}$ films first decreased and then increased relative to that of pristine $\mathrm{VO}_{2}$ as the ion flux was increased. The pre-edge peak of the $\mathrm{V} \mathrm{K}$ edge from the $\mathrm{Cr}_{-} \mathrm{VO}_{2}$ films with a $\mathrm{Cr}$ ion flux $\geq 10^{13} \mathrm{ions} / \mathrm{cm}^{2}$ showed no temperature-dependent behavior, implying no changes in the local density of states of $\mathrm{V} 3 \mathrm{~d} t_{2 \mathrm{~g}}$ and $e_{\mathrm{g}}$ orbitals during MIT. Extended XAFS (EXAFS) revealed that implanted $\mathrm{Cr}$ and $\mathrm{Co}$ ions and their tracks caused a substantial amount of structural disorder and distortion at both vanadium and oxygen sites. The resistance and XAFS measurements revealed that $\mathrm{VO}_{2}$ experiences a sharp MIT when the distance of $\mathrm{V}-\mathrm{V}$ pairs undergoes an SPT without any transitions in either the $\mathrm{VO}_{6}$ octahedrons or the $\mathrm{V} 3 \mathrm{~d} t_{2 \mathrm{~g}}$ and $e_{\mathrm{g}}$ states. This indicates that the MIT of $\mathrm{VO}_{2}$ occurs with no changes of the crystal fields.

Since Morin reported observing the metal-to-insulator transition (MIT) of $\mathrm{VO}_{2}$ in $1959^{1}, \mathrm{VO}_{2}$ has been widely studied to understand the origin of its $\mathrm{MIT}^{2-7}$ and to use it in practical applications including smart windows, batteries, transistors, ultrafast switches, and gas sensors ${ }^{8-15}$. The MIT of $\mathrm{VO}_{2}$ can be induced by different factors such as heat, an electric field, doping, oxygen vacancy, photons, and a magnetic field ${ }^{1,5-7,16-20}$. A typical critical temperature $\left(\mathrm{T}_{c}\right)$ of the MIT of $\mathrm{VO}_{2}$ is approximately $68^{\circ} \mathrm{C}^{5}$. However, previous studies showed that the $\mathrm{T}_{c}$ is very sensitive to structural strain ${ }^{21-23}$. Cao and coworkers observed that $\mathrm{VO}_{2}$ beams with multiple domains have different $T_{c}$ values, resulted in a dull transition ${ }^{22}$. Since the $\mathrm{MIT}$ of $\mathrm{VO}_{2}$ is accompanied by a first-order structural phase transition (SPT) from a monoclinic phase (M1) to a rutile phase (R) via a M2 phase, which is a mixture of the M1 and R phases, the structural changes could be related to the MIT. For the last half decade, arguments have continued as to whether this structural transition directly induces the MIT of $\mathrm{VO}_{2}{ }^{2-8,24-26}$. The electrical resistivity change of $\mathrm{VO}_{2}$ between insulator and metallic phases is approximately four orders of magnitude and the MIT is quite abrupt ${ }^{5,7}$. Many efforts have been made to understand the mechanism of $\mathrm{VO}_{2} \mathrm{MIT}_{\text {both }}$ theoretically and experimentally ${ }^{2-8,24-29}$. Many researchers attributed the abrupt MIT of $\mathrm{VO}_{2}$ to the SPT ${ }^{2,3,24,25,30}$, while others argued that the abrupt MIT can be induced by the change of carriers from holes (insulator) to electrons (metal), supporting the Mott transition of $\mathrm{VO}_{2}{ }^{8,18}$. The abruptness of the $\mathrm{MIT}$ of $\mathrm{VO}_{2}$ has become a further issue, in addition to its origin.

A single crystal $\mathrm{VO}_{2}$ has a distinct MIT temperature 22,31 while the MIT of grained $\mathrm{VO}_{2}$ is dull, occurring over a wide range of temperature ${ }^{7,21}$. The $\mathrm{T}_{\mathrm{c}}$ and the MIT curve of $\mathrm{VO}_{2}$ are very sensitive to structural disorder and strain $^{19,32-34}$. When a $\mathrm{VO}_{2}$ film consists of grains, their structural disorder and distortion can take various forms, resulting in each grain having an individual $\mathrm{T}_{\mathrm{c}}$. Furthermore, Qazilbash demonstrated that the $\mathrm{MIT}_{\mathrm{T}}$ of $\mathrm{VO}_{2}$ could occur at slightly different temperatures for even the same grain by using infrared (IR) mapping measurements ${ }^{5}$. Structural disorder and defects can prevent the movement of conduction electrons and also demolish a bandgap, creating bands of impurity near the Fermi level ${ }^{35}$. As a result, the $\mathrm{T}_{\mathrm{c}}$ of MIT can shift towards a higher or lower temperature ${ }^{21-23}$. Structural disorder, strain, and defects can be created by different conditions, including

${ }^{1}$ Department of Physics Education, Institute of Fusion Science, and Institute of Science Education, Jeonbuk National University, Jeonju 54896, Korea. ${ }^{2}$ X-ray Science Division, Advanced Photon Source, Argonne National Laboratory, Lemont, IL 60439, USA. ${ }^{3}$ Korea Atomic Energy Research Institute, KOMAC, Miraero 181, Gyoungju 38180, Korea. ${ }^{\circledR}$ email: shan@jbnu.ac.kr 


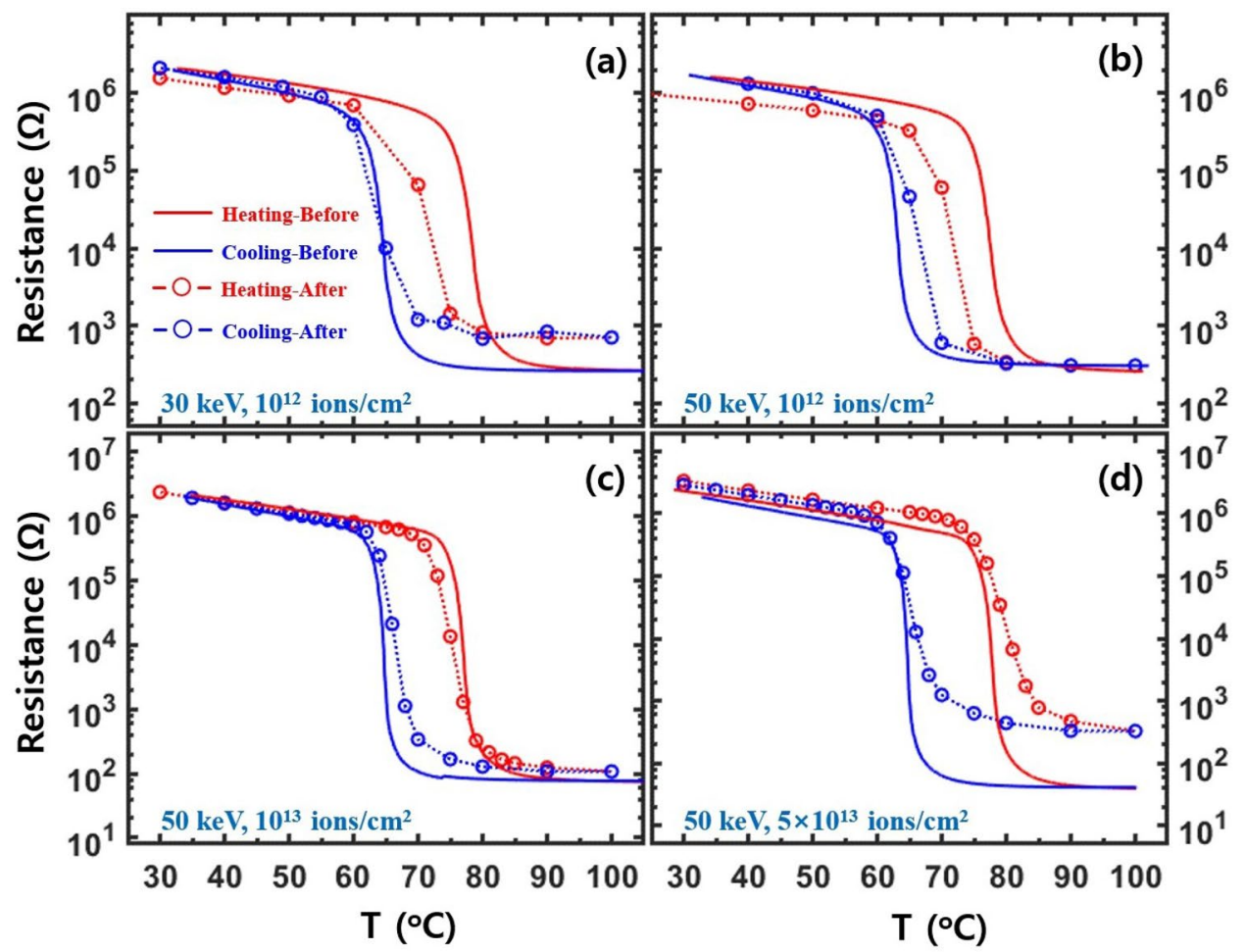

Figure 1. Temperature-dependent electrical resistance for $\mathrm{Cr}-\mathrm{VO}_{2}$ films with a $\mathrm{Cr}$ ion energy and a flux of (a) $30 \mathrm{keV}$ and $10^{12} \mathrm{ions} / \mathrm{cm}^{2}$, (b) $50 \mathrm{keV}$ and $10^{12} \mathrm{ions} / \mathrm{cm}^{2}$, (c) $50 \mathrm{keV}$ and $10^{13} \mathrm{ions} / \mathrm{cm}^{2}$, and (d) $50 \mathrm{keV}$ and $5 \times 10^{13}$ ions $/ \mathrm{cm}^{2}$, respectively. Solid lines and circles are the resistances for the same $\mathrm{Cr}-\mathrm{VO}_{2}$ film before and after Cr-ion implantation, respectively. XAFS was simultaneously measured at the temperatures of the circles. Red and blue colors indicate the resistance for heating and cooling processes, respectively. The dotted lines are a guide for the eye.

impurities, grain boundaries, and lattice mismatch between film and substrate ${ }^{21,22,33}$. For practical applications of $\mathrm{VO}_{2}$, the $\mathrm{T}_{c}$, the abruptness, and the resistance difference between metallic and insulating phases of its MIT are the most important parameters.

The $\mathrm{T}_{\mathrm{c}}$ and the MIT features of $\mathrm{VO}_{2}$ with various impurities, including $\mathrm{Cr}$, Co, W, Mo, and Ti, have been examined ${ }^{17,37-44}$. Added impurities in $\mathrm{VO}_{2}$ act as dopants, create structural disorder, and distort the atomic bond lengths ${ }^{17,42,44}$. Previous studies showed that the $\mathrm{T}_{\mathrm{c}}$ of $\mathrm{V}_{1-\mathrm{x}} \mathrm{Cr}_{\mathrm{x}} \mathrm{O}_{2}$ shifted towards a higher temperature while it was observed at lower temperatures from $\mathrm{V}_{1-\mathrm{x}} \mathrm{Co}_{\mathrm{x}} \mathrm{O}_{2}, \mathrm{~V}_{1-\mathrm{x}} \mathrm{W}_{\mathrm{x}} \mathrm{O}_{2}$, and $\mathrm{V}_{1-\mathrm{x}} \mathrm{Mo}_{\mathrm{x}} \mathrm{O}_{2}$ relative to that of pure $\mathrm{VO}_{2}{ }^{17,37-44}$. $\mathrm{Cr}^{3+}$ and $\mathrm{Co}^{2+}$ impurities in $\mathrm{VO}_{2}$ increased and decreased the $\mathrm{T}_{c}$, respectively, with little effect on the abruptness and the sharpness of the MIT curves ${ }^{38,42}$, although the chemical valence states of both $\mathrm{Cr}^{3+}$ and $\mathrm{Co}^{2+}$ are smaller than the $4+$ of $\mathrm{V}$ in $\mathrm{VO}_{2}$. Added impurities in $\mathrm{VO}_{2}$ can influence the density of charge carriers in a conduction band and the structural properties and density of states. The in-situ electrical resistance and X-ray absorption fine structure (XAFS) measurements of $\mathrm{Cr}$ - and Co-ion implanted $\mathrm{VO}_{2}\left(\mathrm{Cr}-\mathrm{VO}_{2}\right.$ and $\left.\mathrm{Co}-\mathrm{VO}_{2}\right)$ were used to examine the contribution of local structural properties on the MIT of $\mathrm{VO}_{2}$. Since in a single crystal $\mathrm{VO}_{2}$, the correlation of the electrons (Mott insulator), the structural-driven Peierls distortion, and the crystal field effects of metal-oxide octahedrons simultaneously change with MIT at the same temperature, their contributions to MIT are indistinguishable. The contribution of a parameter on MIT can be distinguished from the others only when it does not occur simultaneously with the other parameters.

\section{Results}

The temperature-dependent electrical properties of $\mathrm{Cr}$ - and $\mathrm{Co}_{-} \mathrm{VO}_{2}$. Implanted $\mathrm{Cr}$ and $\mathrm{Co}$ ions can act as dopants and induce structural defects in $\mathrm{VO}_{2}$. Previous studies showed that the lattice constants of Crdoped $\mathrm{VO}_{2}$ increased ${ }^{37,39}$ while the $\mathrm{T}_{\mathrm{c}}$ shifted towards a higher temperature ${ }^{38,39}$. Figure 1 shows the temperaturedependent resistance from the $\mathrm{Cr}-\mathrm{VO}_{2}$ films before and after $\mathrm{Cr}$-ions implantation. The typical $\mathrm{T}_{\mathrm{c}}$ value of single crystal $\mathrm{VO}_{2}$ is approximately $68^{\circ} \mathrm{C}^{5,31}$. However, the $\mathrm{T}_{\mathrm{c}}$ value of a $\mathrm{VO}_{2}$ film is substantially affected by structural strain and disorder and varies according to the substrate $e^{21,32,32}$. The $\mathrm{T}_{\mathrm{c}}$ of $\sim 78{ }^{\circ} \mathrm{C}$ for the pristine $\mathrm{VO}_{2}$ films in Fig. 1 before the ion implantation is ascribed to structural strain due to a lattice mismatch between the $\mathrm{VO}_{2}$ films and $\mathrm{Al}_{2} \mathrm{O}_{3}$ substrates ${ }^{21,33,34}$. The $\mathrm{T}_{\mathrm{c}}$ values of pristine $\mathrm{VO}_{2}$ films in Fig. 2, particularly in Fig. 2(c), are somewhat lower than that in Fig. 1. The $\mathrm{T}_{\mathrm{c}}$ values suggest that the growth conditions of $\mathrm{VO}_{2}$ films in Fig. 1 were somewhat different from those in Fig. 2, although the difference was not conscious during growth. A small deviation of the characteristics of the pristine $\mathrm{VO}_{2}$ films does not seriously affect the main conclusions of this study because the changes of MIT features before and after ion implantation are directly compared from the same specimen. The 


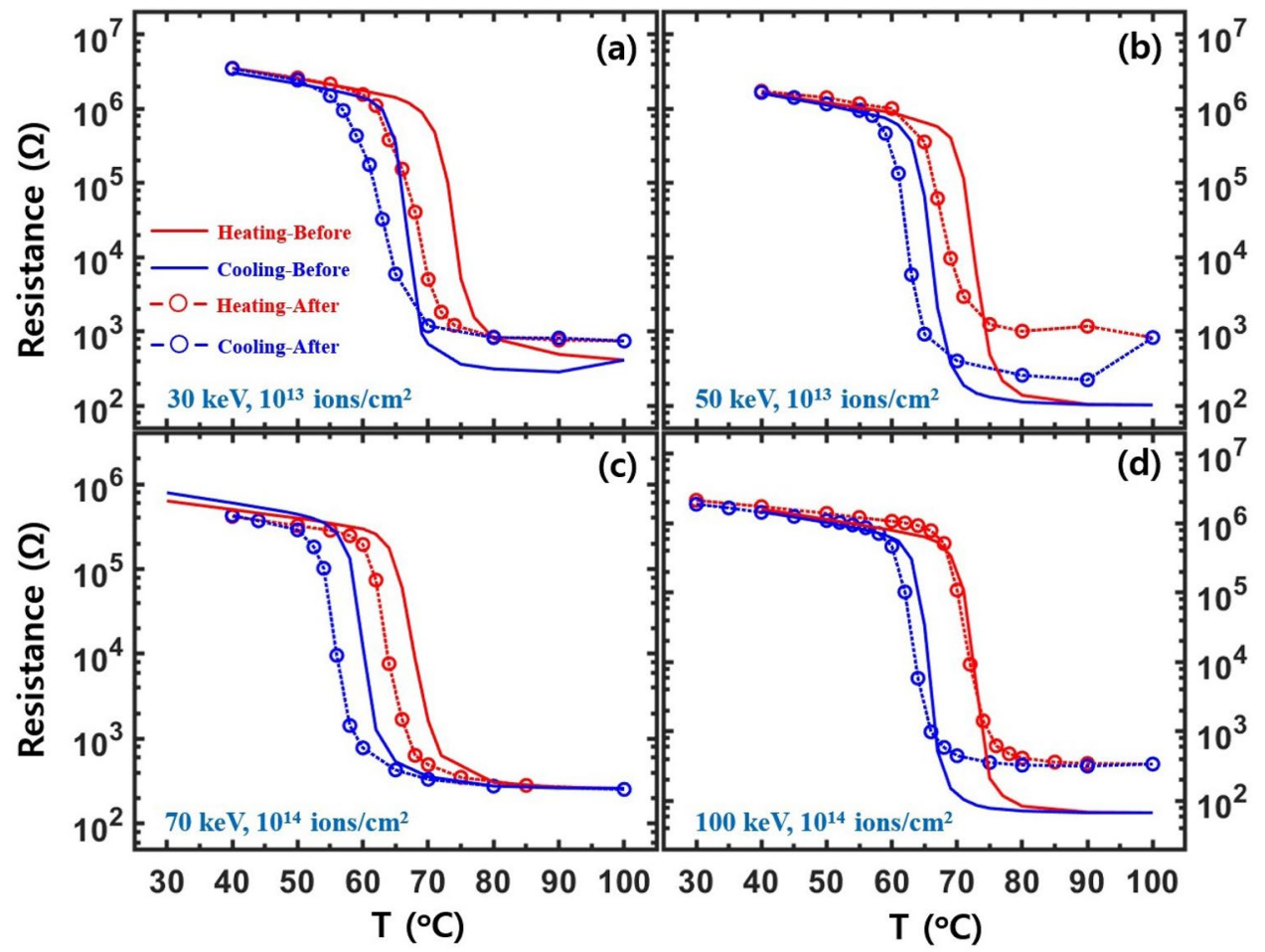

Figure 2. Temperature-dependent electrical resistance for $\mathrm{Co}-\mathrm{VO}_{2}$ films with a Co ion energy and a flux of (a) $30 \mathrm{keV}$ and $10^{13}$ ions $/ \mathrm{cm}^{2}$, (b) $50 \mathrm{keV}$ and $10^{13} \mathrm{ions} / \mathrm{cm}^{2}$, (c) $70 \mathrm{keV}$ and $10^{14} \mathrm{ions} / \mathrm{cm}^{2}$, and (d) $100 \mathrm{keV}$ and $10^{14}$ ions $/ \mathrm{cm}^{2}$, respectively. Solid lines and circles are the resistances for the same Co- $\mathrm{VO}_{2}$ film before and after Co-ion implantation, respectively. XAFS was simultaneously measured at the temperatures of the circles. Red and blue colors indicate resistance for heating and cooling processes, respectively. The dotted lines are a guide for the eye.

resistance curves of the $\mathrm{Cr}-\mathrm{VO}_{2}$ films with a flux of $10^{12}$ ions $/ \mathrm{cm}^{2}$ show that the $\mathrm{T}_{\mathrm{c}}$ values during heating and cooling shift towards lower and higher temperatures relative to those before $\mathrm{Cr}$ ion implantation, respectively. As a result, the width of a hysteresis loop from the $\mathrm{Cr}-\mathrm{VO}_{2}$ films, particularly with a low energy of Cr ions, is significantly narrower than that of the pristine $\mathrm{VO}_{2}$. For Cr ion fluxes of $10^{13}$ ions $/ \mathrm{cm}^{2}$ and $5 \times 10^{13}$ ions $/ \mathrm{cm}^{2}$, the resistance curves become similar to that of the pristine $\mathrm{VO}_{2}$. At a flux of $5 \times 10^{13} \mathrm{ions} / \mathrm{cm}^{2}$, the $\mathrm{T}_{\mathrm{c}}$ value is $\sim 2$ degrees higher than that before ion implantation, as shown in Fig. 1(d). This is consistent with the previous studies of $\mathrm{V}_{1-\mathrm{x}} \mathrm{Cr}_{\mathrm{x}} \mathrm{O}$ in which the $\mathrm{T}_{\mathrm{c}}$ was shifted towards a higher temperature ${ }^{38,39}$. The $\mathrm{T}_{\mathrm{c}}$ increase of 2 degrees of $\mathrm{Cr}-\mathrm{VO}_{2}$ roughly corresponds to the $\mathrm{Cr}$ concentration of $\sim 3 \%$, compared to a previous study of $\mathrm{V}_{1-\mathrm{x}} \mathrm{Cr}_{\mathrm{x}} \mathrm{O}_{2}{ }^{39}$. The $\mathrm{T}_{\mathrm{c}}$ shift and the resistance changes of $\mathrm{Cr}-\mathrm{VO}_{2}$ can be understood in terms of structural disorder and doping effects due to implanted $\mathrm{Cr}$ ions. The structural damage due to implanted ions is discussed in detail in the supplementary materials.

Zou and coworkers reported that the width of the hysteresis loop of temperature-dependent resistance for $\mathrm{VO}_{2}$ was reduced by $\mathrm{Cr}$ doping and that the MIT features of $\mathrm{VO}_{2}$ disappeared at a $\mathrm{Cr}$ concentration ratio of $14 \%^{39}$. The resistance measurements of the $\mathrm{Cr}$ - and $\mathrm{Co}-\mathrm{VO}_{2}$ films show that the MIT characteristics of $\mathrm{VO}_{2}$ mostly disappear when the flux of $\mathrm{Cr}$ and $\mathrm{Co}$ ions exceeds $10^{15}$ ions $/ \mathrm{cm}^{2}$, which corresponds to $~ 50 \%$ of the $\mathrm{VO}_{2}$ cells being hit by implanted ions. The probability of a conventional cell of a film being hit by implanted ions can be estimated as $P(x)=1-A \int_{0}^{x} F(x) d x$, where $F(\mathrm{x})$ is the distribution function of ions in a film and $A$ is the normalization factor. The details of the probability are described in the supplementary materials. The ion tracks and the local disorder due to implanted ions likely destroy the MIT characteristics. The $\mathrm{T}_{\mathrm{c}}$ shift of the $\mathrm{Cr}-\mathrm{VO}_{2}$ films with an ion flux of $10^{12}$ ions $/ \mathrm{cm}^{2}$ suggests that the structural disorder due to ion implantation dominantly contributes to the electrical properties because of the negligible doping effect at a concentration ratio of $0.00023 \%$. The concentration ratio is discussed in the supplementary materials in detail. When the ion flux increases over $10^{13}$ ions $/ \mathrm{cm}^{2}$, the doping effects due to the implanted ions may influence the MIT of $\mathrm{VO}_{2}$ because of the extremely low charge carrier density of insulating $\mathrm{VO}_{2}$, although structural disorder still dominantly affects the MIT.

Figure 2 shows the temperature-dependent electrical resistance of the $\mathrm{Co}-\mathrm{VO}_{2}$ films with different fluxes and energies of $\mathrm{Co}$ ions. The distribution of implanted $\mathrm{Co}$ ions in $\mathrm{VO}_{2}$ is quite similar to that of $\mathrm{Cr}$ ions, as shown in the supplementary materials. When Co ions with a flux of $10^{13} \mathrm{ions} / \mathrm{cm}^{2}$ and an energy of $\leq 70 \mathrm{keV}$ are implanted on $\mathrm{VO}_{2}$ films, the $\mathrm{T}_{c}$ values for both heating and cooling processes shift towards lower temperatures relative to those before the ion implantation. This is consistent with Co-doped $\mathrm{VO}_{2}{ }^{42}$. The width reduction of the resistance hysteresis loop is similar to that of the $\mathrm{Cr}-\mathrm{VO}_{2}$ films with low ion fluxes. The resistance curves of the Co- $\mathrm{VO}_{2}$ films with an energy of 30-50 keV and a flux of $10^{14}$ ions $/ \mathrm{cm}^{2}$ show very weak MIT features near the $\mathrm{T}_{\mathrm{c}}$ of $65^{\circ} \mathrm{C}$ (data 

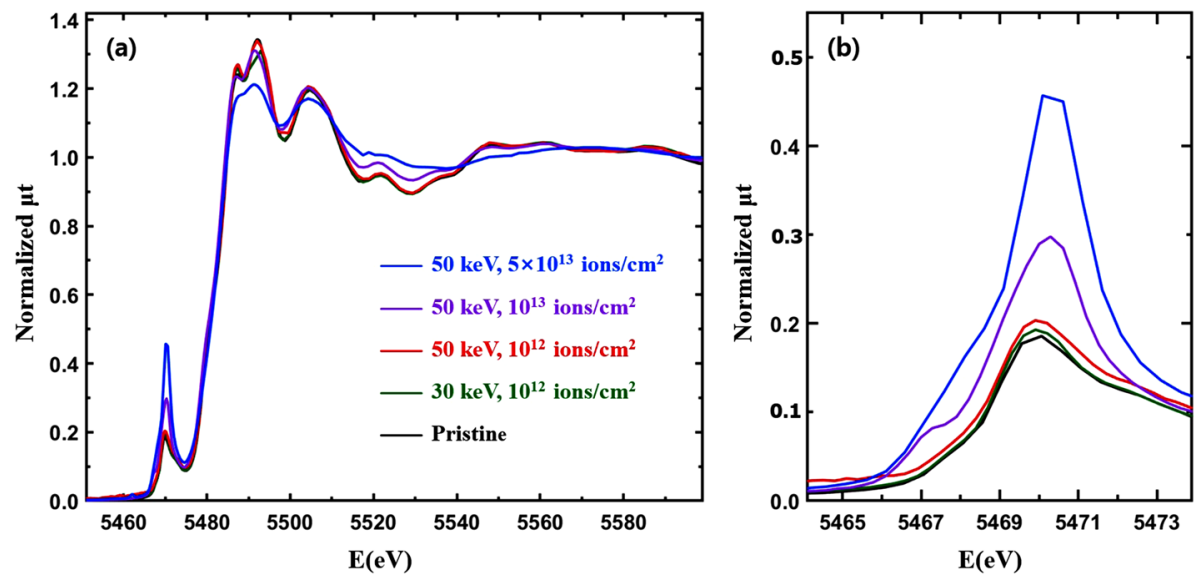

Figure 3. (a) Normalized total $\mathrm{X}$-ray absorption ( $\mu \mathrm{t})$ for $\mathrm{Cr}-\mathrm{VO}_{2}$ films with different $\mathrm{Cr}$ energies and fluxes at the $\mathrm{V} \mathrm{K}$ edge as a function of the incident X-ray energy at the room temperature. The films are the same as those used for the resistance measurements, as shown in Fig. 1, and (b) is a magnified image of the pre-edge peaks in (a).

not shown here). When the energy of Co ions is increased over $70 \mathrm{keV}$ with a flux of $10^{14} \mathrm{ions} / \mathrm{cm}^{2}$, the $\mathrm{Co}-\mathrm{VO}_{2}$ films show sharp MIT features, as shown in Fig. 2(c, d). SRIM calculations ${ }^{45}$ showed that the Co ions with an energy of $30 \mathrm{keV}$ can become concentrated near the surface of a single crystal $\mathrm{VO}_{2}$. Since our $\mathrm{VO}_{2}$ films consist of grains with a mean size of $\sim 170 \mathrm{~nm}^{36}$, implanted ions with the energy of 30-50 keV can affect the entire film through the grain boundaries and the lateral surfaces of the grains ${ }^{46}$. A lack of MIT features in $\mathrm{Co}-\mathrm{VO}_{2}$ with a Co ion energy of $30 \mathrm{keV}$ and a flux of $10^{14}$ ions $/ \mathrm{cm}^{2}$ (data not shown here) can be ascribed to a substantial structural disorder and distortion existing in the entire film due to the ion implantation. Structural disorder and distortion in $\mathrm{Cr}$ - and $\mathrm{Co}-\mathrm{VO}_{2}$ films which are created due to the implanted ions may not be uniformly distributed and can be more concentrated on near the surface than the bottom because the ion energy of several tens keV is insufficient to create a uniform defect in $\mathrm{VO}_{2}$ films with a mean thickness of $\sim 130 \mathrm{~nm}$.

At a Co ion energy of $100 \mathrm{keV}$, the resistance curves of the $\mathrm{Co}-\mathrm{VO}_{2}$ films show sharp MIT features and the $\mathrm{T}_{\mathrm{c}}$ values become similar to those before implantation during both heating and cooling. This is substantially different from those for a low energy of Co ions and sharply contrasts to previous works of Co-added $\mathrm{VO}_{2}{ }^{42}$. The ion-flux-dependent behavior of $\mathrm{T}_{\mathrm{c}}$ values of $\mathrm{Co}-\mathrm{VO}_{2}$ is similar to that of $\mathrm{Cr}-\mathrm{VO}_{2}$, as shown in Fig. 1. As the flux of both $\mathrm{Co}$ and $\mathrm{Cr}$ ions exceeds a certain value, $\mathrm{T}_{\mathrm{c}}$ shifts towards a higher and lower temperature relative to that for a low flux during heating and cooling, respectively, while the sharpness of MIT is not greatly affected, as shown in Figs. 1 and 2. A similar behavior of $\mathrm{T}_{\mathrm{c}}$ was also observed from Ti-added $\mathrm{VO}_{2}{ }^{44}$. When the flux of $\mathrm{Cr}$ and Co ions with the energy of $30-50 \mathrm{keV}$ is larger than $10^{14} \mathrm{ions} / \mathrm{cm}^{2}$, the MIT features are significantly diminished. The critical flux of the ions increases when ion energy increases, as shown in Fig. 2. This is an evidence that ions with a lower energy more effectively create structural disorder, particularly near the surface, than the ions with a higher energy.

The temperature-dependent XANES and the pre-edge peaks of $\mathrm{Cr}-\mathrm{VO}_{2}$ and $\mathrm{Co}-\mathrm{VO}_{2}$. Implanted $\mathrm{Cr}^{3+}$ and $\mathrm{Co}^{2+}$ ions can affect the charge currier density of conduction bands and the local density of states around the $\mathrm{V}$ atoms in $\mathrm{VO}_{2}$. X-ray absorption near edge structure (XANES) detects the local density of empty states around a probing atom ${ }^{7}$. Figure 3 shows XANES from the $\mathrm{Cr}-\mathrm{VO}_{2}$ films at the $\mathrm{V} \mathrm{K}$ edge. The main absorption edge energy near $5478 \mathrm{eV}$ from the $\mathrm{Cr}-\mathrm{VO}_{2}$ films is nearly identical to that of a pristine $\mathrm{VO}_{2}$ film, which indicates that the chemical valance state and the $4 \mathrm{p}$ states of the $\mathrm{V}$ atoms in $\mathrm{VO}_{2}$ are little affected by implanted $\mathrm{Cr}$ ions at a flux $\leq 5 \times 10^{13}$ ions $/ \mathrm{cm}^{2}$. The intensity of the pre-edge peak near $5470 \mathrm{eV}$ from the $\mathrm{Cr}-\mathrm{VO}_{2}$ films increases dramatically for an ion flux $\geq 10^{13}$ ions $/ \mathrm{cm}^{2}$, but only increases slightly for a flux of $10^{12}$ ions $/ \mathrm{cm}^{2}$ relative to that of the pristine $\mathrm{VO}_{2}$. The pre-edge peaks consist of two peaks corresponding to the $t_{2 \mathrm{~g}}$ and $e_{\mathrm{g}}$ states of $\mathrm{V} 3 \mathrm{~d}$ orbitals of $\mathrm{VO}_{2}$, which are separated by approximately $2.0 \mathrm{eV}^{7}$. The intensity increase of the pre-edge peak at the $\mathrm{V} \mathrm{K}$ edge was also observed from Ti-added $\mathrm{VO}_{2}{ }^{44}$. Since a lack of doping effects is expected when $\mathrm{Ti}^{4+} \mathrm{s}$ are replaced at $\mathrm{V}^{4+}$ sites in $\mathrm{VO}_{2}$, the pre-edge peak changes are mainly attributed to structural changes around the $\mathrm{V}$ atoms. The position of the pre-edge peak is shifted by approximately $0.5 \mathrm{eV}$ for a Cr ion flux $\geq 10^{13}$ ions $/ \mathrm{cm}^{2}$ relative to that of the pristine $\mathrm{VO}_{2}$, as shown in Fig. 3 (b). These intensity increases and the position shift of the pre-edge peak might be due to local structural distortion around the $\mathrm{V}$ atoms.

Figure 4(a,b) show the temperature-dependent XANES and pre-edge peaks, respectively, from a pristine $\mathrm{VO}_{2}$ film in the temperature range of $30-100^{\circ} \mathrm{C}$. The main absorption edge is almost unaffected by the increasing temperature while the pre-edge shows a temperature-dependent behavior. In a pristine $\mathrm{VO}_{2}$ film, the dull pre-edge peak corresponds to the $t_{2 \mathrm{~g}}$ and $e_{\mathrm{g}}$ bands which have the energy difference of $\sim 2.0 \mathrm{eV}^{7}$. The direct band gap of $\mathrm{VO}_{2}$ is $\sim 0.65 \mathrm{eV}$ at room temperature ${ }^{47,48}$ and the Fermi level lies in the lower $t_{2 \mathrm{~g}}$ band $\mathrm{d}^{2,3,7}$. Figure 3(d) shows that the intensity of the pre-edge peak decreases and the position shifts towards a higher energy when $\mathrm{VO}_{2}$ is heated from 30 to $100^{\circ} \mathrm{C}$. The separation of the two pre-edge peaks does not change greatly but the peak 

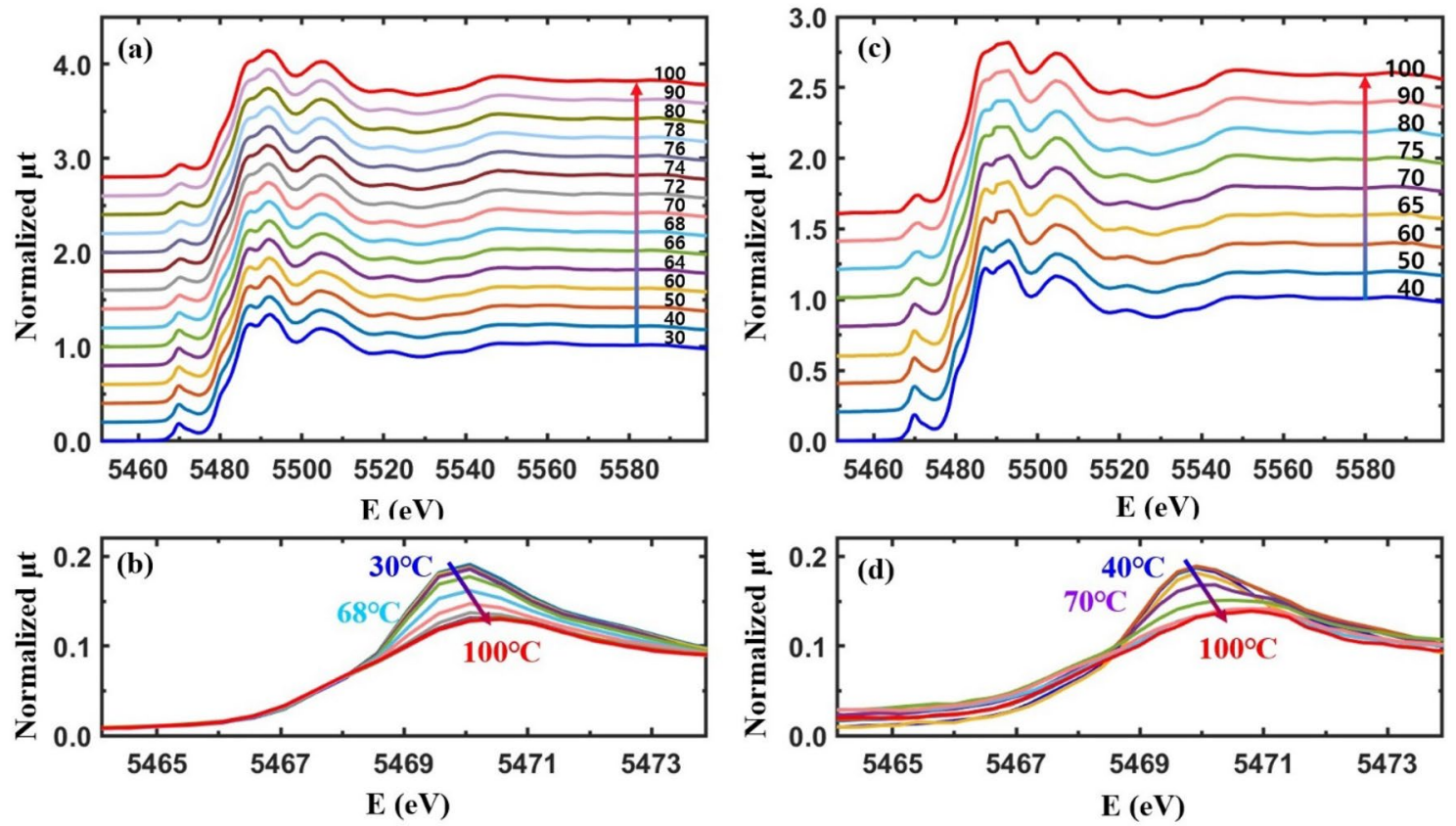

Figure 4. (a, c) Normalized temperature-dependent XANES ( $\mu \mathrm{t})$ from a pristine $\mathrm{VO}_{2}$ film and the $\mathrm{Cr}-\mathrm{VO}_{2}$ film with a $\mathrm{Cr}$ ion energy of $30 \mathrm{keV}$ and a flux of $10^{12}$ ions $/ \mathrm{cm}^{2}$ during heating. (b, d) are the magnified images of the pre-edge peaks in $(\mathbf{a}, \mathbf{c})$, respectively. Data in $(\mathbf{a}, \mathbf{c})$ are vertically shifted for clarity.

positions shift by $\sim 0.5 \mathrm{eV}$ towards a higher energy when the structural symmetry of $\mathrm{VO}_{2}$ changes from $\mathrm{M} 1$ to a rutile (or M2) phase $\mathrm{f}^{7}$. The pre-edge peak of the pristine $\mathrm{VO}_{2}$ shows a shift at $\sim 68^{\circ} \mathrm{C}$, as shown in Fig. 4 (b). This is prior to the $\mathrm{T}_{\mathrm{c}}$ of $\sim 75^{\circ} \mathrm{C}$. The temperature-dependent behavior of the pre-edge peak is directly related to the local structural changes around the $\mathrm{V}$ atoms ${ }^{7}$.

Electrical resistance measurements from $\mathrm{Cr}-\mathrm{VO}_{2}$ films with even a low $\mathrm{Cr}$ ion flux show substantial changes in the $\mathrm{T}_{\mathrm{c}}$ value of the MIT relative to that before ion implantation, as shown in Fig. 1. XANES and the pre-edge peak reveal that a $\mathrm{Cr}-\mathrm{VO}_{2}$ film with a small flux of $\mathrm{Cr}$ ions shows similar behavior as that of pristine $\mathrm{VO}_{2}$, as shown in Fig. 4(c, d). The pre-edge peak from the $\mathrm{Cr}-\mathrm{VO}_{2}$ film shifts at $\sim 68{ }^{\circ} \mathrm{C}$ and $\sim 65^{\circ} \mathrm{C}$ while the $\mathrm{T}_{\mathrm{c}}$ values of MIT are $71^{\circ} \mathrm{C}$ and $\sim 65^{\circ} \mathrm{C}$ during heating and cooling, respectively, as shown in Fig. 1(a). The pre-edge peak transitions roughly agree with the MITs of the film, although they do not occur simultaneously at the same temperature. This is consistent with pristine $\mathrm{VO}_{2}{ }^{7}$. For a Cr ion flux $\geq 10^{13} \mathrm{ions} / \mathrm{cm}^{2}$, the intensity of the pre-edge dramatically increases relative to that of pristine $\mathrm{VO}_{2}$ while the resistance curves are comparable to that before ion implantation. Figure 5(a,c) show the temperature-dependent XANES of the $\mathrm{Cr}-\mathrm{VO}_{2}$ films with a flux $\geq 10^{13}$ ions $/ \mathrm{cm}^{2}$. The pre-edge peaks of the films show nearly no temperature dependence in the temperature range of $40-100{ }^{\circ} \mathrm{C}$. This sharply contrasts to that of pristine $\mathrm{VO}_{2}$ and $\mathrm{Cr}-\mathrm{VO}_{2}$ with a low flux of the $\mathrm{Cr}$ ion beam. The resistance curves of the $\mathrm{Cr}-\mathrm{VO}_{2}$ films show clear MIT features, as shown in Fig. 1(c, d). This temperature independence of the pre-edge peaks of the $\mathrm{Cr}-\mathrm{VO}_{2}$ films is obvious evidence confirming that the pre-edge peak at the $\mathrm{V}$ K edge is irrelevant to the $\mathrm{MIT}$ of $\mathrm{VO}_{2}$. The pre-edge peak of a single crystal $\mathrm{VO}_{2}$ accidently changes with temperature due to the transition of local structural properties and the local density of states around the $\mathrm{V}$ atoms. This study suggests that a structural disorder can remove the correlation between the pre-edge peak and the electrical properties of $\mathrm{VO}_{2}$.

Figure 6(a) shows XANES at the $\mathrm{V}$ K edge from $\mathrm{Co}-\mathrm{VO}_{2}$ films with different energies and Co ion fluxes. The main absorption edges of the $\mathrm{Co}-\mathrm{VO}_{2}$ films are nearly identical to that of pristine $\mathrm{VO}_{2}$. This confirms the permanence of both the chemical valance states and the local density of states around the $\mathrm{V}$ atoms in the $\mathrm{Co}-\mathrm{VO}_{2}$ films, relative to those of the pristine $\mathrm{VO}_{2}$ film. The intensity of the pre-edge peaks slightly increases at a Co ion flux of $10^{14}$ ions $/ \mathrm{cm}^{2}$. The XANES of $\mathrm{Co}-\mathrm{VO}_{2}$ films is quite different from that of $\mathrm{Cr}-\mathrm{VO}_{2}$ films, as shown in Fig. 3. Figure 6(c) shows the temperature-dependent XANES of $\mathrm{Co}-\mathrm{VO}_{2}$ with a Co ion energy of $70 \mathrm{keV}$ and a flux of $10^{14}$ ions $/ \mathrm{cm}^{2}$. No significant changes in the main absorption edge energy of the $\mathrm{Co}-\mathrm{VO}_{2}$ film are observed in the temperature range of $30-100^{\circ} \mathrm{C}$. The pre-edge peak behavior of $\mathrm{Co}-\mathrm{VO}_{2}$ is similar to that of the pristine $\mathrm{VO}_{2}$ but it is completely different from that of $\mathrm{Cr}-\mathrm{VO}_{2}$ with a $\mathrm{Cr}$ flux $\geq 10^{13}$ ions $/ \mathrm{cm}^{2}$. The pre-edge peak shifts at $62^{\circ} \mathrm{C}$ towards a higher energy, as shown in Fig. 6(d), which is slightly prior to the $\mathrm{T}_{\mathrm{c}}$ of $65^{\circ} \mathrm{C}$, as shown in Fig. 2(c). The different behaviors of the pre-edge peaks from the $\mathrm{Cr}-\mathrm{VO}_{2}$ and $\mathrm{Co}-\mathrm{VO}_{2}$ films are mainly attributed to the different local structural properties around the $\mathrm{V}$ atoms.

Local structural properties around vanadium atoms of $\mathrm{Cr}^{-} \mathrm{VO}_{2}$ and $\mathrm{Co}-\mathrm{VO}_{2}$. Extended XAFS (EXAFS), which is small oscillations above the main absorption edge, as partially shown in Figs. 3, 4, 5 and 6, can detect the local structural properties around a probing atom ${ }^{50-52}$. After the atomic background was determined using the IFEFFIT software package ${ }^{53}$, EXAFS was obtained and analyzed using the standard procedure ${ }^{54}$. 

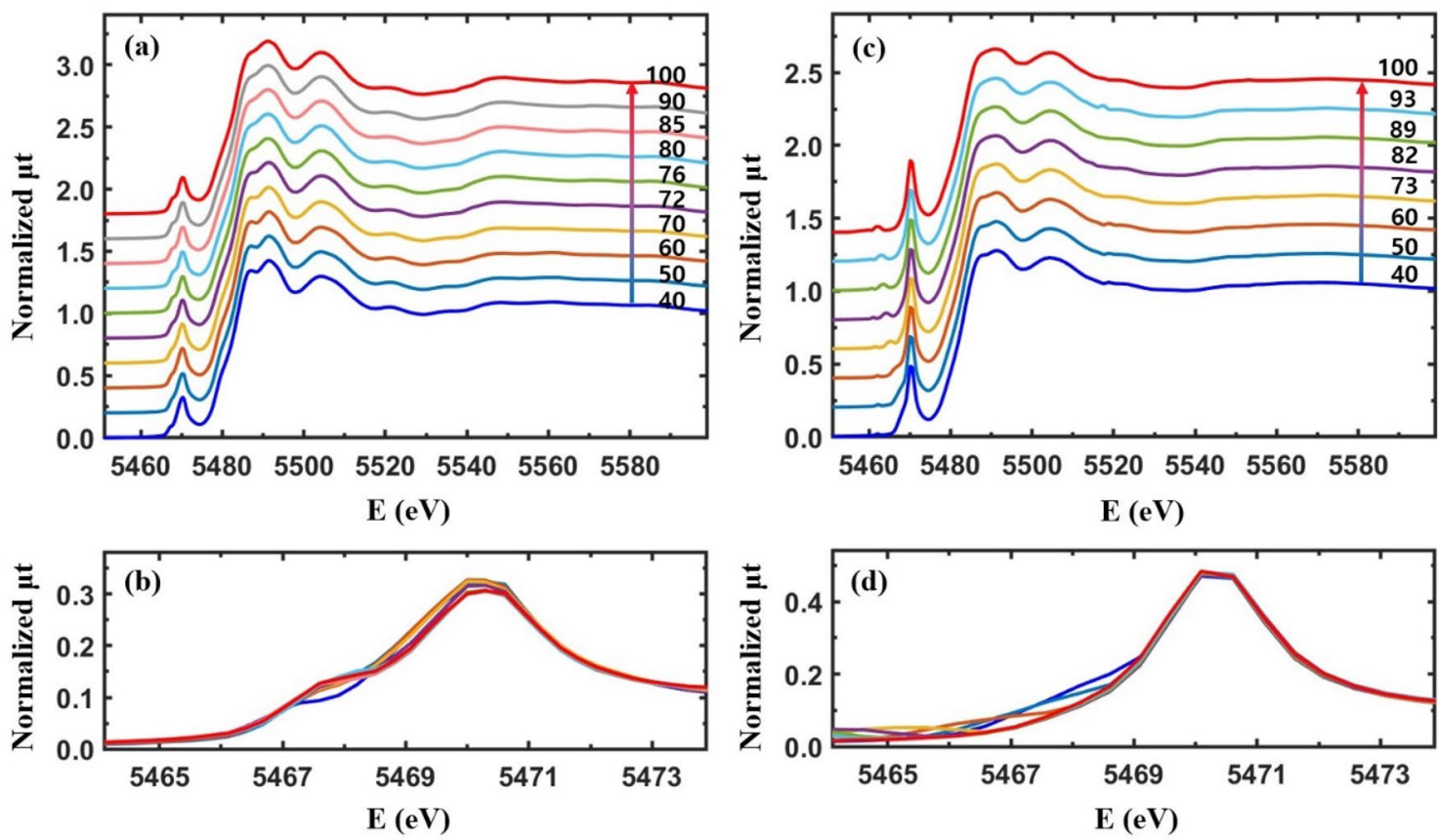

Figure 5. (a, c) Temperature-dependent XANES from $\mathrm{Cr}-\mathrm{VO}_{2}$ films with a $\mathrm{Cr}$ energy of $50 \mathrm{keV}$ and fluxes of $10^{13}$ ions $/ \mathrm{cm}^{2}$ and $5 \times 10^{13}$ ions $/ \mathrm{cm}^{2}$, respectively. $(\mathbf{b}, \mathbf{d})$ are the magnified images of the pre-edge peaks in $(\mathbf{a}, \mathbf{c})$, respectively. Data in (a, c) are vertically shifted for clarity.
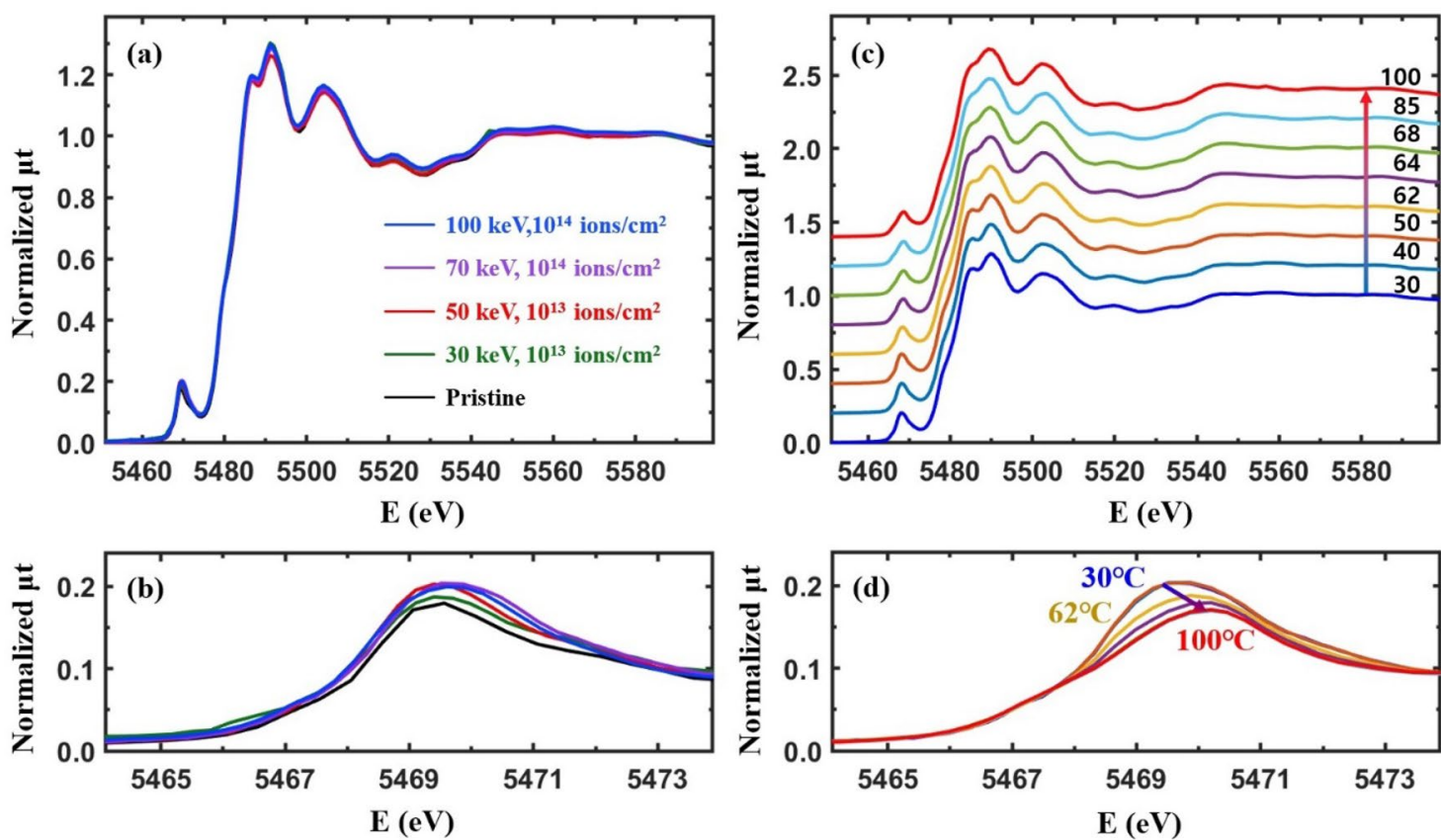

Figure 6. (a) Normalized total X-ray absorption ( $\mu \mathrm{t})$ for $\mathrm{Co}-\mathrm{VO}_{2}$ films with different Co ion energies and fluxes at the $\mathrm{V}$ K edge as a function of the incident X-ray energy at room temperature. The films are the same as those in Fig. 2. (c) Temperature-dependent XANES for $\mathrm{Co}-\mathrm{VO}_{2}$ with a Co energy of $70 \mathrm{keV}$ and a flux of $10^{14}$ ions/ $\mathrm{cm}^{2}$. (b, d) are the magnified images of the pre-edge peaks in $(\mathbf{a}, \mathbf{c})$, respectively. Data in (c) are vertically shifted for clarity.

Raw EXAFS in $k$-space is presented in the supplementary materials. Figure 7 shows Fourier transformed EXAFS from the pristine $\mathrm{VO}_{2}$ and $\mathrm{Cr}-\mathrm{VO}_{2}$ films in $r$-space. The peak positions of EXAFS correspond to the mean atomic distances from a V atom. They are approximately $0.3 \AA$ shorter than the true atomic positions because the phase shift of back-scattered photoelectrons is not accounted for. Figure $7(a, b)$ show temperature-dependent EXAFS for the pristine $\mathrm{VO}_{2}$ film for heating and cooling, respectively. The two peaks near $1.5 \AA$ correspond to the six 


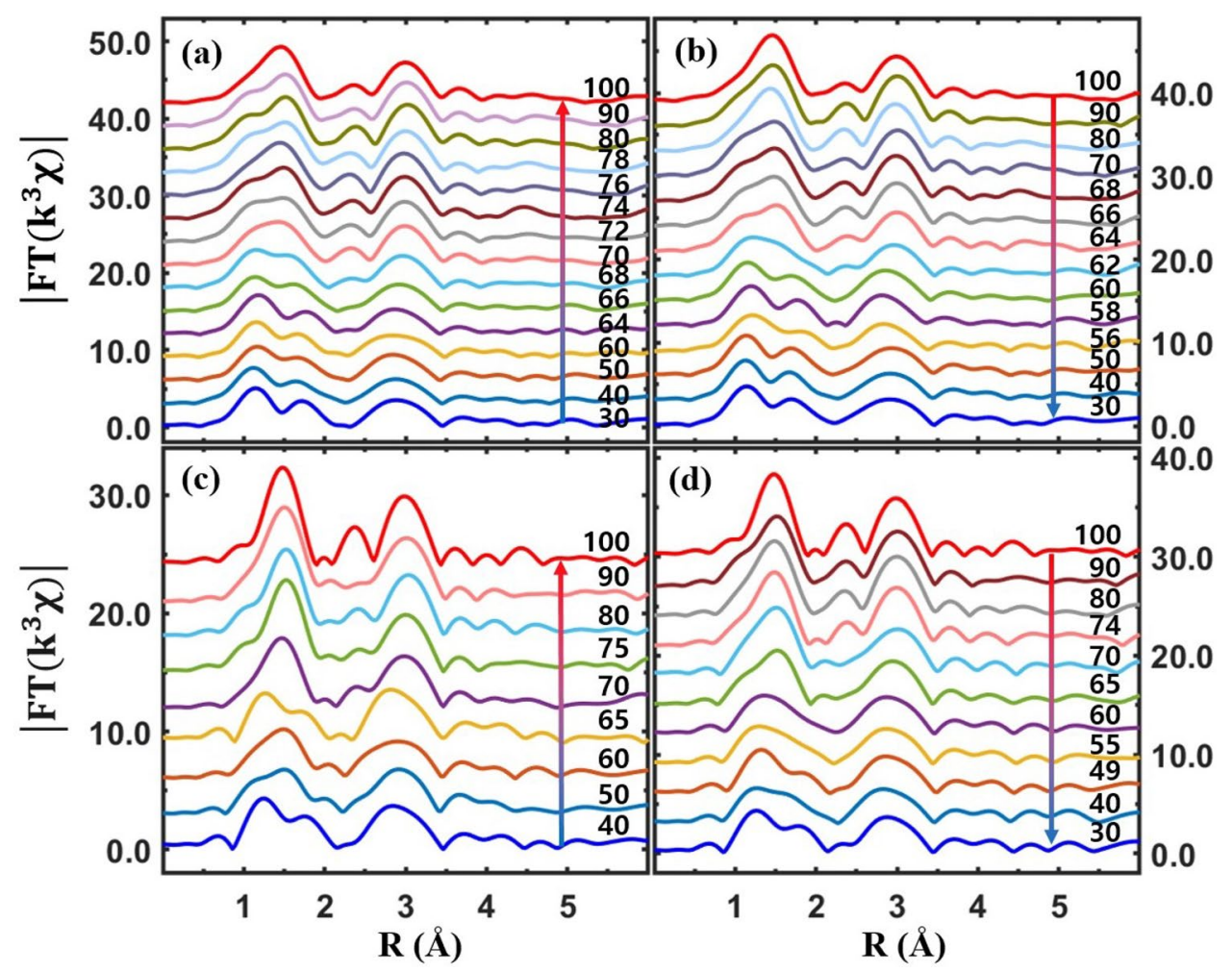

Figure 7. Magnitude of Fourier transformed EXAFS $\left(\left|\mathrm{FT}\left(\mathrm{k}^{3} \chi\right)\right|\right)$ as a function of the distance from a V atom at different temperatures. (a, b) EXAFS from pristine $\mathrm{VO}_{2}$ for heating and cooling, respectively. (c, d) EXAFS from $\mathrm{Cr}-\mathrm{VO}_{2}$ with a $\mathrm{Cr}$ ion energy of $50 \mathrm{keV}$ and a flux of $10^{12}$ ions $/ \mathrm{cm}^{2}$ for heating and cooling, respectively. The data are vertically shifted for clarity.

$\mathrm{V}-\mathrm{O}$ pairs of a $\mathrm{VO}_{6}$ octahedron in $\mathrm{VO}_{2}$ at lower temperatures; these become one sharp peak at higher temperatures because $\mathrm{VO}_{2}$ has monoclinic and rutile (or M2) phases at low and high temperatures, respectively. A peak near 3.0 $\AA$, mainly corresponding to eight vertex $\mathrm{V}$ atoms, slightly moves towards a longer distance in the rutile (or M2) phase, compared to that in M1. The EXAFS data of a pristine $\mathrm{VO}_{2}$ were quantitatively fitted to the EXAFS theory ${ }^{51}$ and the fit results are described elsewhere in literatures ${ }^{7,36}$. The SPTs of the pristine $\mathrm{VO}_{2}$ film are observed at $\sim 70^{\circ} \mathrm{C}$ and $\sim 62^{\circ} \mathrm{C}$ for heating and cooling, respectively. The SPT temperatures do not match with either the $\mathrm{T}_{c}$ of MIT or the pre-edge peak transitions. This agrees with previous reports ${ }^{7,33}$. From the $\mathrm{Cr}-\mathrm{VO}_{2}$ film with a Cr ion energy of $50 \mathrm{keV}$ and a flux of $10^{12}$ ions $/ \mathrm{cm}^{2}$, the SPTs are observed at $68^{\circ} \mathrm{C}$ and $63{ }^{\circ} \mathrm{C}$ for heating and cooling, respectively, as shown in Fig. 7(c,d). The temperature difference between the SPTs for heating and cooling is approximately $5{ }^{\circ} \mathrm{C}$, which is comparable to the resistance curve after ion-implantation, as shown in Fig. 1(a). This strongly suggests that the electrical property changes and the $\mathrm{T}_{\mathrm{c}}$ shifts of $\mathrm{Cr}^{-} \mathrm{VO}_{2}$ films are highly related to the structural changes due to ion implantation. In addition, this indicates that the implanted $\mathrm{Cr}$ ions with the energy of $50 \mathrm{keV}$ cause structural disorder and distortion around $\mathrm{V}$ atoms in the entire $\mathrm{Cr}-\mathrm{VO}_{2}$ film.

An obvious MIT is observed from the $\mathrm{Cr}-\mathrm{VO}_{2}$ films with a flux of $\mathrm{Cr}$ ions $\geq 10^{13}$ ions $/ \mathrm{cm}^{2}$ with no changes of the pre-edge peaks in the temperature range of $30-100{ }^{\circ} \mathrm{C}$. Figure 8 shows EXAFS from the $\mathrm{Cr}^{-} \mathrm{VO}_{2}$ films with a Cr ion flux $\geq 10^{13}$ ions $/ \mathrm{cm}^{2}$. At this $\mathrm{Cr}$ ion flux, there are clear SPTs near $72{ }^{\circ} \mathrm{C}$ and $64{ }^{\circ} \mathrm{C}$ for heating and cooling, respectively, as shown in Fig. 8(a,b). The SPT temperatures are comparable to the MIT $\mathrm{T}_{\mathrm{c}}$ values of $75^{\circ} \mathrm{C}$ and $65^{\circ} \mathrm{C}$ for heating and cooling, respectively, as shown in Fig. 1(c). This result is substantially different from that of a pristine $\mathrm{VO}_{2}$, which shows very different the $\mathrm{T}_{\mathrm{c}}$ values of MIT and SPT during both heating and cooling. The similar $\mathrm{T}_{\mathrm{c}}$ values of the MIT and the SPT in $\mathrm{Cr}-\mathrm{VO}_{2}$ and $\mathrm{Co}-\mathrm{VO}_{2}$ may suggest that $\mathrm{Cr}-$ and $\mathrm{Co}-\mathrm{VO}_{2}$ films structurally soften relative to a pristine $\mathrm{VO}_{2}$ film due to ion implantation. Figure 8(c, d) show Fouriertransformed EXAFS of $\mathrm{Cr}-\mathrm{VO}_{2}$ with a flux of $5 \times 10^{13}$ ions $/ \mathrm{cm}^{2}$. EXAFS shows no SPT of the first two peaks in 1.0-2.0 $\AA$ in the temperature range of $40-100^{\circ} \mathrm{C}$, indicating no SPT of the $\mathrm{VO}_{6}$ octahedron in $\mathrm{Cr}-\mathrm{VO}_{2}$. There are slight changes in the position and the shape of the EXAFS peaks in the $r$-range of 2.2-3.3 $\AA$, as shown in Fig. 8(c, d), which correspond to ten $\mathrm{V}$ atoms: two $\mathrm{V}$ atoms are located above and below along the $b$-axis and the other eight are located at the vertexes of the rutile $\mathrm{VO}_{2}$. The position and the shape of the $\mathrm{V}$ peak near $3.0 \AA$ are evidently changed at the $\mathrm{T}_{\mathrm{c}}$ of the SPT of a pristine $\mathrm{VO}_{2}$. A small shift of the $\mathrm{V}$ peak of the $\mathrm{Cr}-\mathrm{VO}_{2}$ film with a flux of $5 \times 10^{13}$ ions $/ \mathrm{cm}^{2}$ occurs at $73^{\circ} \mathrm{C}$ and $61^{\circ} \mathrm{C}$ for heating and cooling, respectively. The small shift of the $\mathrm{V}$ peak is reproducible and consistent during heating and cooling processes, although it is quite weak. The $\mathrm{T}_{c}$ values of sharp MITs from the $\mathrm{Cr}-\mathrm{VO}_{2}$ film are observed at $80^{\circ} \mathrm{C}$ and $65^{\circ} \mathrm{C}$ for heating and cooling, respectively, as shown in Fig. 1(d). No transitions in either the pre-edge peak or in the V-O distance of the $\mathrm{Cr}_{-} \mathrm{VO}_{2}$ film with a flux of $5 \times 10^{13}$ ions $/ \mathrm{cm}^{2}$ are observed, whereas a small shift occurs in the $\mathrm{V}-\mathrm{V}$ distance. This indicates that 


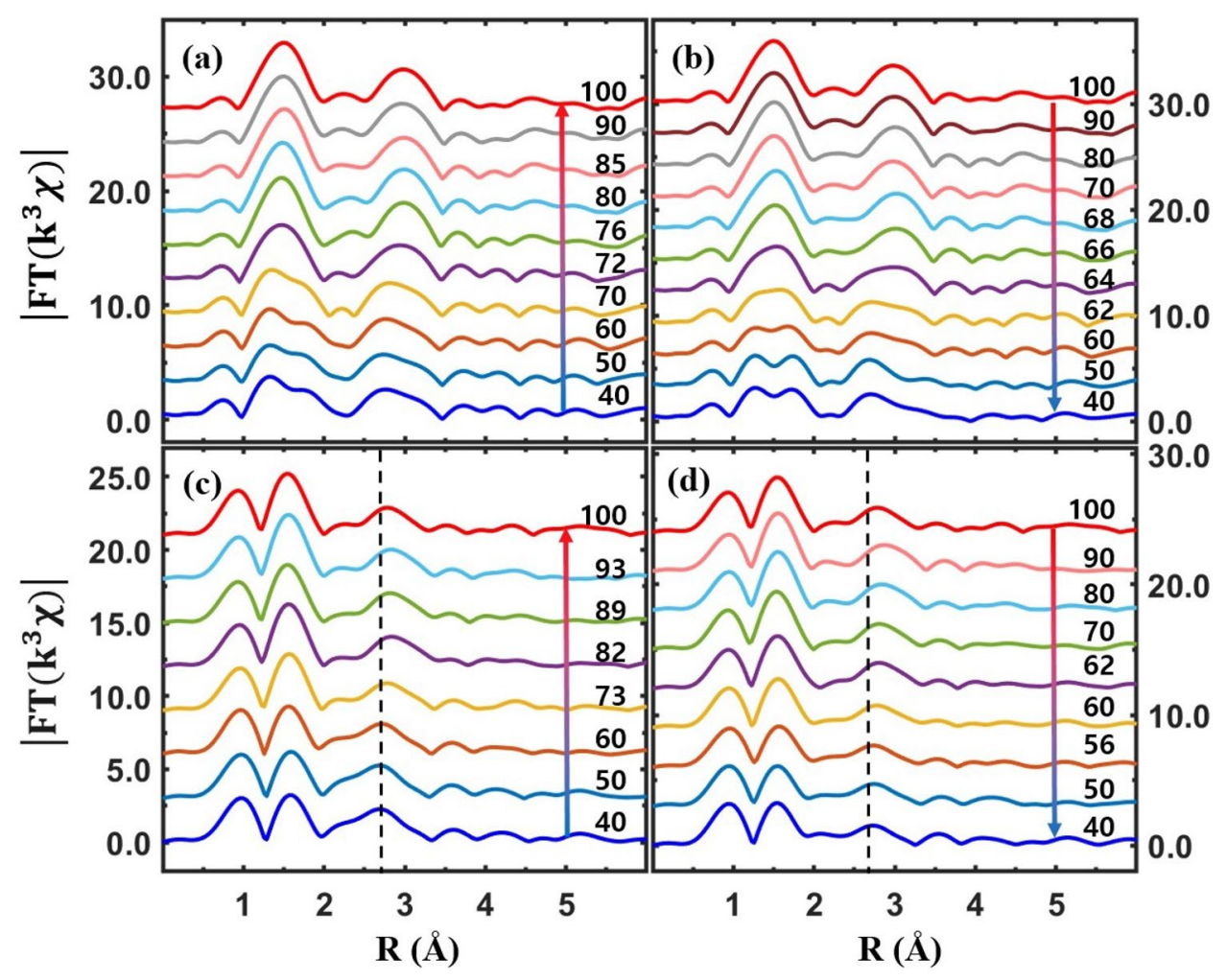

Figure 8. Magnitude of Fourier transformed EXAFS $\left(\left|\mathrm{FT}\left(\mathrm{k}^{3} \chi\right)\right|\right)$ as a function of the distance from a $\mathrm{V}$ atom at different temperatures. $(\mathbf{a}, \mathbf{b})$ EXAFS of $\mathrm{Cr}-\mathrm{VO}_{2}$ with a $\mathrm{Cr}$ ion energy of $50 \mathrm{keV}$ and a flux of $10^{13} \mathrm{ions} / \mathrm{cm}^{2}$ for heating and cooling, respectively. (c, d) EXAFS of $\mathrm{Cr}-\mathrm{VO}_{2}$ with a $\mathrm{Cr}$ ion energy of $50 \mathrm{keV}$ and a flux of $5 \times 10^{13}$ ions $/ \mathrm{cm}^{2}$ for heating and cooling, respectively. The data are vertically shifted for clarity. The vertical dashed lines indicate the position of eight $\mathrm{V}$ atoms located at the vertexes of a rutile $\mathrm{VO}_{2}$.

both the pre-edge peak and the $\mathrm{VO}_{6}$ octahedron, which are directly related to the crystal field effects, are nearly irrelevant to the MIT of $\mathrm{VO}_{2}$. The structural change of the $\mathrm{V}$ sites could drive the MIT of $\mathrm{VO}_{2}$, although the V sites cannot maintain even a correct rutile symmetry above the $\mathrm{T}_{\mathrm{c}}$ due to structural disorder. The transitions of the pre-edge peaks and the $\mathrm{VO}_{6}$ octahedrons occur accidentally with the SPT of $\mathrm{VO}_{2}$ crystals because the pre-edge peak is very sensitive to the nearest neighboring atoms around a probing atom and the $\mathrm{V}-\mathrm{O}$ distance changes with the SPT. The EXAFS of the $\mathrm{Cr}-\mathrm{VO}_{2}$ films suggests that a structural change of the V sites is related to the MIT, although the temperatures of the structural changes are not identical to the $\mathrm{T}_{\mathrm{c}}$ values of the MIT during both heating and cooling.

Figure $9(\mathrm{a}, \mathrm{b})$ show temperature-dependent EXAFS from $\mathrm{Co}-\mathrm{VO}_{2}$ with a Co ion flux of $10^{14} \mathrm{ions} / \mathrm{cm}^{2}$. EXAFS shows the SPTs of the films occurring at $\sim 62{ }^{\circ} \mathrm{C}$ and $\sim 56^{\circ} \mathrm{C}$ for heating and cooling, respectively, which are comparable to the $\mathrm{T}_{\mathrm{c}}$ values of $65^{\circ} \mathrm{C}$ and $55^{\circ} \mathrm{C}$, as shown in Fig. 2(c). The SPT of Co- $\mathrm{VO}_{2}$ simultaneously appears at both $\mathrm{O}$ and $\mathrm{V}$ atomic sites at the same temperature. The SPT of Co- $\mathrm{VO}_{2}$ is similar to that of pristine $\mathrm{VO}_{2}$ but it is quite different from that of $\mathrm{Cr}-\mathrm{VO}_{2}$ with a $\mathrm{Cr}$ ion flux of $5 \times 10^{13} \mathrm{ions} / \mathrm{cm}^{2}$. The distortion of atomic pairs in $\mathrm{Cr}-\mathrm{VO}_{2}$ and $\mathrm{Co}-\mathrm{VO}_{2}$ is more obviously seen when the EXAFS data are directly compared to those of pristine $\mathrm{VO}_{2}$, as shown in Fig. 9(c, d). The EXAFS of pristine $\mathrm{VO}_{2}$ shows two obvious peaks in the $r$-space of 1.0-2.0 $\AA$, which correspond to six V-O pairs. When the ion flux increases, the EXAFS peak intensity is decreased, the shape is deformed, and the positions are shifted relative to those of the pristine $\mathrm{VO}_{2}$. The significant deformation of the first two peaks of the $\mathrm{Cr}$-and $\mathrm{Co}-\mathrm{VO}_{2}$ films indicates that the $\mathrm{VO}_{6}$ octahedrons are seriously distorted due to the implanted ions. When the flux of $\mathrm{Cr}$ ions is larger than $5 \times 10^{13}$ ions $/ \mathrm{cm}^{2}, \mathrm{VO}_{2}$ cannot maintain standard $\mathrm{VO}_{6}$ octahedrons. EXAFS reveals that for an ion energy of $50 \mathrm{keV}$ and a flux of $10^{13} \mathrm{ions} / \mathrm{cm}^{2}$, the first peaks of $\mathrm{Co}-\mathrm{VO}_{2}$ are more distorted than that of $\mathrm{Cr}-\mathrm{VO}_{2}$. The second peak of EXAFS at $\sim 3.0 \AA$, which mainly corresponds to eight $\mathrm{V}$ atoms at the vertexes of a rutile phase $\mathrm{VO}_{2}$, is also affected by the implanted ions but the distortion of the V-V pairs is less significant than that of the V-O pairs, as shown in Fig. 9(c, d). For a Cr ion flux of $10^{12}$ ions/ $\mathrm{cm}^{2}$, the intensity and the shape of the second peak from $\mathrm{Cr}-\mathrm{VO}_{2}$ with an energy of both $30 \mathrm{keV}$ and $50 \mathrm{keV}$ are similar to those of the pristine $\mathrm{VO}_{2}$, implying that the $\mathrm{V}$ sites are slightly affected by the implanted $\mathrm{Cr}$ ions. As the ion flux increases, the structural distortion of the $\mathrm{V}$ sites also increases in both $\mathrm{Cr}-\mathrm{VO}_{2}$ and $\mathrm{Co}-\mathrm{VO}_{2}$. When the energy of Co ions becomes $100 \mathrm{keV}$, structural distortion, particularly at $\mathrm{V}$ sites, is somewhat reduced, compared to that at low ion energy, as shown in Fig. 9(d). This is not observed in $\mathrm{Cr}-\mathrm{VO}_{2}$. The positions and shapes of the EXAFS peaks from $\mathrm{Cr}-\mathrm{VO}_{2}$ with a $\mathrm{Cr}$ ion flux of $5 \times 10^{13}$ ions $/ \mathrm{cm}^{2}$ are significantly different from those of other specimens, implying serious distortion existing in all atomic sites. Interestingly, the position and shape of the third two peaks near $4.0 \AA$ in Fig. 9 (c, d) are similar to those of the pristine $\mathrm{VO}_{2}$, although the intensity 


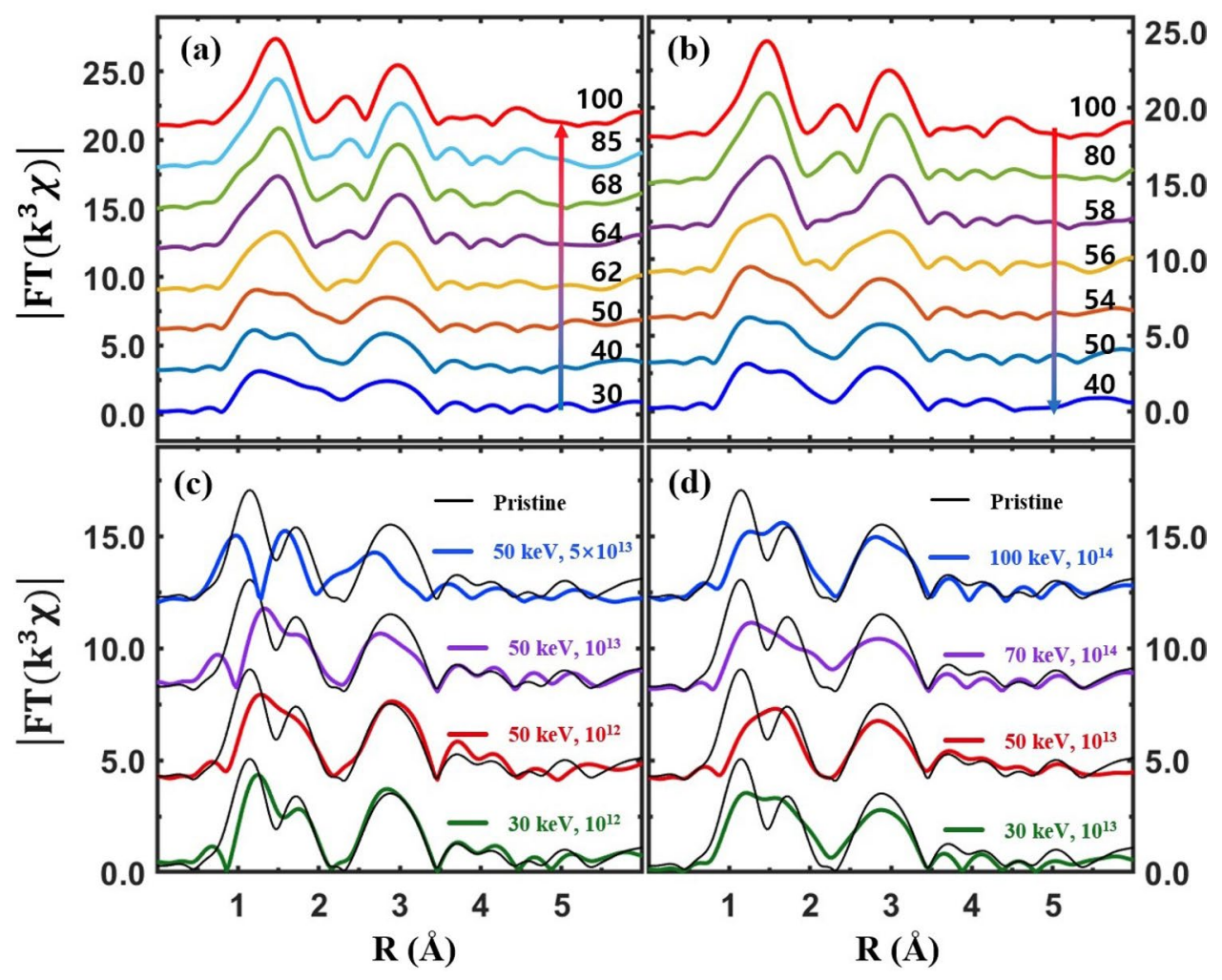

Figure 9. (a, b) EXAFS $\left(\left|\mathrm{FT}\left(\mathrm{k}^{3} \chi\right)\right|\right)$ from $\mathrm{Co}-\mathrm{VO}_{2}$ with a Co ion energy of $70 \mathrm{keV}$ and a flux of $10^{14}$ ions $/ \mathrm{cm}^{2}$ for heating and cooling, respectively. (c, d) EXAFS of $\mathrm{Cr}-\mathrm{VO}_{2}$ and $\mathrm{Co}-\mathrm{VO}_{2}$ films with different energies and fluxes, respectively, at room temperature. The data are vertically shifted for clarity.

is quite weak. The third peaks mainly correspond to further $\mathrm{V}$ atomic shells beyond a conventional cell of a rutile-phased $\mathrm{VO}_{2}$. Those peaks of $\mathrm{Cr}-\mathrm{VO}_{2}$ with a flux of $5 \times 10^{13} \mathrm{ions} / \mathrm{cm}^{2}$ show a slight temperature-dependent behavior, as shown Fig. 8(c, d). This is a further evidence that the $\mathrm{V}$ sites of $\mathrm{Cr}-\mathrm{VO}_{3}$ with a flux of $5 \times 10^{13}$ ions/ $\mathrm{cm}^{2}$ still experience a weak SPT during both heating and cooling processes.

\section{Discussion}

Many researchers have observed that the MIT of a single crystal $\mathrm{VO}_{2}$ occurs simultaneously with its SPT at $\mathrm{T}_{\mathrm{c}} \approx 68^{\circ} \mathrm{C}^{5,29}$. Since the MIT of $\mathrm{VO}_{2}$ is accompanied by an SPT, the contribution of each structural change, such as $\mathrm{VO}_{6}$ octahedrons, $\mathrm{V}-\mathrm{V}$ dimers, and vertex $\mathrm{V}$ arrays, on the MIT is indistinguishable because the changes occur simultaneously in a single crystal $\mathrm{VO}_{2}$. EXAFS from $\mathrm{Cr}-\mathrm{VO}_{2}$ and $\mathrm{Co}-\mathrm{VO}_{2}$ films shows independent changes of structural properties of atomic shells during MIT. The direct comparison of electrical resistance and EXAFS measurements suggests that the contribution of the $\mathrm{VO}_{6}$ octahedrons on the MIT is negligible. The energy states of $\mathrm{V} 3 \mathrm{~d}$ orbitals are split in the $e_{\mathrm{g}}$ and $t_{2 \mathrm{~g}}$ bands due to the crystal field effects of a $\mathrm{VO}_{6}$ octahedron in $\mathrm{VO}_{2}$. In $\mathrm{Cr}-\mathrm{VO}_{2}$ with a flux $\geq 10^{13}$ ions $/ \mathrm{cm}^{2}$ the $\mathrm{V}-\mathrm{O}$ pairs are significantly disordered, so that the $\mathrm{VO}_{6}$ octahedrons cannot have regular splitting of the $e_{\mathrm{g}}$ and $t_{2 \mathrm{~g}}$ bands. This prevents any regular alignment of $\mathrm{V} 3 \mathrm{~d}$ orbitals in the specimen and can exclude the possibility of conduction electrons jumping from a lower energy band of the $d_{x y}$ and $d_{x z}$ orbitals to a higher energy band of the $d_{\|}\left(d_{x^{2}-y^{2}}\right)$ to trigger the metallic phase $\mathrm{VO}_{2}$. A lack of temperaturedependent features of the pre-edge peak from $\mathrm{Cr}-\mathrm{VO}_{2}$ with a flux $\geq 10^{13}$ ions $/ \mathrm{cm}^{2}$ is further evidence of no regular splitting of $\mathrm{V} 3 \mathrm{~d}$ states because the pre-edge peak corresponds to the $e_{\mathrm{g}}$ and $t_{2 \mathrm{~g}}$ bands ${ }^{7}$. A dramatic increase of the pre-edge peak intensity of $\mathrm{Cr}-\mathrm{VO}_{2}$ indicates an increase of local density of states in the $\mathrm{V} 3 \mathrm{~d}$ orbitals due to the structural distortion of $\mathrm{VO}_{6}$ octahedrons. The pre-edge peak intensity of the $\mathrm{V}$ K edge increased and decreased for $\mathrm{V}_{2} \mathrm{O}_{5}$ and $\mathrm{V}_{2} \mathrm{O}_{3}$, respectively, relative to that of $\mathrm{VO}_{2}$, because there are more empty states in the $\mathrm{V}$ 3d orbitals of $\mathrm{V}_{2} \mathrm{O}_{5}$ than of $\mathrm{V}_{2} \mathrm{O}_{3}{ }^{41,55}$.

The dull pre-edge peak of $\mathrm{VO}_{2}$ at the $\mathrm{V} \mathrm{K}$ edge consists of two peaks which correspond to the $\mathrm{V} 3 \mathrm{~d} t_{2 \mathrm{~g}}$ and $e_{\mathrm{g}}$ states, respectively, with an energy gap of $\sim 2.0 \mathrm{eV}^{7}$. XANES cannot detect the direct band gap because of its resolution limit. XANES from pristine $\mathrm{VO}_{2}$ shows that the intensities of the $t_{2 \mathrm{~g}}$ (lower peak) and $e_{\mathrm{g}}$ (upper peak) states decreases and increases, respectively, with no change of the band gap between the two states during heating ${ }^{7}$. As a result, the pre-edge peak seems to be shifted towards a higher energy for heating, as shown in Fig. $4(\mathrm{~b}, \mathrm{~d})$. The pre-edge peaks of $\mathrm{Cr}-\mathrm{VO}_{2}$ with a flux $\geq 10^{13}$ ions $/ \mathrm{cm}^{2}$ show that the $t_{2 \mathrm{~g}}$ band at $\sim 5467.5 \mathrm{eV}$ nearly disappears while the peak intensity of the $e_{\mathrm{g}}$ states at $\sim 5469.5 \mathrm{eV}$ is very strong with no temperature dependence, as shown in Fig. 5(b, d). For the $\mathrm{Cr}-\mathrm{VO}_{2}$ films with a flux $\geq 10^{13}$ ions $/ \mathrm{cm}^{2}$, the lack temperature dependence of the pre-edge peak strongly implies no changes in the local density of states of the $\mathrm{V} 3 \mathrm{~d}$ orbitals in the temperature 
range of $30-100^{\circ} \mathrm{C}$, although the films experience MIT and SPT. This is evidence indicating that the $t_{2 \mathrm{~g}}$ and $e_{\mathrm{g}}$ bands split by the crystal field effects are irrelevant to the MIT of $\mathrm{VO}_{2}$ and that an SPT of short-range orderings around the $\mathrm{V}$ atoms in $\mathrm{VO}_{2}$ does not directly contribute to the MIT. EXAFS shows an SPT and no SPT at the $\mathrm{O}$ sites of $\mathrm{Cr}-\mathrm{VO}_{2}$ with a flux of $10^{13}$ and $5 \times 10^{13}$ ions $/ \mathrm{cm}^{2}$, respectively, while an SPT is observed at the $\mathrm{V}$ sites for both fluxes. This implies that the pre-edge peak of $\mathrm{VO}_{2}$ is mainly contributed by the nearest neighboring $\mathrm{O}$ atoms, rather than by the second neighboring $\mathrm{V}$ atoms. This contrasts to the previous studies of the pre-edge peak of transition metals, in which the authors discussed the contribution of the second neighboring atoms on the pre-edge peaks $s^{41,44,56}$.

On the other hand, traditional band theory cannot predict the bandgap of $\sim 0.65 \mathrm{eV}$ for M1-phased $\mathrm{VO}_{2}$ at room temperature ${ }^{6}$. Based on a structural-driven Peierls transition mechanism, two different distances of $\mathrm{V}-\mathrm{V}$ pairs in $\mathrm{M} 1 \mathrm{VO}_{2}$ were introduced to understand the insulating phase of $\mathrm{VO}_{2}{ }^{6,27,57-60}$. The dimerization model also cannot explain the measured bandgap of $\mathrm{VO}_{2}$ at room temperature ${ }^{6}$. Our EXAFS measurements and calculations [Supplementary Materials] on $\mathrm{Cr}-\mathrm{VO}_{2}$ with a $\mathrm{Cr}$ flux of $5 \times 10^{13}$ ions $/ \mathrm{cm}^{2}$ reveal a substantial amount of structural disorder at both oxygen and vanadium sites. The linear defects created due to the implanted ions are placed perpendicular to the current direction in the DC electrical resistance measurements of the films. $\mathrm{Cr}_{-} \mathrm{VO}_{2}$ barely maintains a crystalline structure without regular V-V dimers and does not show an SPT of V-V dimers due to the enormous amount of structural disorder and distortion in the $\mathrm{V}$ sites, although there are obvious MITs during both heating and cooling. The distances of the $\mathrm{V}-\mathrm{V}$ dimers are approximately $\sim 2.5 \AA$ and $\sim 3.2 \AA$ in the M1 phase and become $\sim 2.8 \AA$ in the rutile phase ${ }^{27,36}$. Our result is further evidence that a V-V dimerization model cannot explain the MIT mechanism of $\mathrm{VO}_{2}$. However, a structural-driven Peierls transition may not be excluded as an explanation for the MIT of $\mathrm{VO}_{2}$ because the EXAFS peaks which mainly correspond to the $\mathrm{V}$ sites show a weak SPT at $\mathrm{T}_{c}$, as shown in Fig. 8(c, d). The sharp MIT features of the resistance curve from $\mathrm{Cr}_{-} \mathrm{VO}_{2}$ with a $\mathrm{Cr}$ ion flux of $5 \times 10^{13}$ ions $/ \mathrm{cm}^{2}$ strongly suggest a transition of interaction between conduction electrons at $\mathrm{T}_{\mathrm{c}}$. The EXAFS and resistance measurements of the $\mathrm{Cr}-\mathrm{VO}_{2}$ film support that the MIT is highly related to the interaction of conduction electrons and is triggered by the alignment of the $\mathrm{V}$ atomic arrays near $\mathrm{T}_{\mathrm{c}}$.

Previous studies reported that the $\mathrm{T}_{\mathrm{c}}$ values of $\mathrm{Cr}$-added and Co-added $\mathrm{VO}_{2}$ shifted towards higher and lower temperatures, respectively ${ }^{37-40,42}$. The $\mathrm{T}_{\mathrm{c}}$ values of both $\mathrm{Cr}$ - and $\mathrm{Co}-\mathrm{VO}_{2}$ films with a flux $\geq 5 \times 10^{13}$ ions/ $\mathrm{cm}^{2}$ shift towards a higher temperature. Since the concentration ratio of the implanted ions is only $\sim 0.023 \%$ for an ion flux of $10^{14}$ ions $/ \mathrm{cm}^{2}$, the doping effects of the ions could be negligible. $\mathrm{V}_{1-\mathrm{x}} \mathrm{Ti}_{\mathrm{x}} \mathrm{O}_{2}$ also showed that the $\mathrm{T}_{\mathrm{c}}$ decreased and increased for low and high concentrations of $\mathrm{Ti}^{4+}$, respectively ${ }^{44} . \mathrm{Ti}^{4+}$ ions which are mostly replaced at the $\mathrm{V}^{4+}$ sites of $\mathrm{VO}_{2}$ can cause the disorder and distortion of the $\mathrm{V}$ sites without doping effects. Previous studies of heavy ion irradiation with high energy on $\mathrm{VO}_{2}$ showed that the resistivity and the $\mathrm{T}_{\mathrm{c}}$ value of $\mathrm{VO}_{2}$ were considerably modified due to an extra structural disorder ${ }^{61,62}$. Hofsäss and coworkers showed that $1 \mathrm{GeV}$ ${ }^{238} \mathrm{U}$ swift heavy ions substantially decreased the $\mathrm{T}_{\mathrm{c}}$ value of $\mathrm{VO}_{2}$, although no surface hillocks were observed ${ }^{61}$. When $200 \mathrm{meV} \mathrm{Ag}{ }^{9+}$-ions with a high flux bombarded $\mathrm{VO}_{2}$, the surface and the crystal symmetry of $\mathrm{VO}_{2}$ were seriously damaged. Both $\mathrm{T}_{\mathrm{c}}$ value and resistivity jump size of the MIT of $\mathrm{VO}_{2}$ continuously decreased when the fluence of $\mathrm{Ag}^{9+}$ ions increased ${ }^{62}$. This result is somewhat different from that of $\mathrm{Cr}-\mathrm{VO}_{2}, \mathrm{Co}-\mathrm{VO}_{2}$, and $\mathrm{V}_{1-\mathrm{x}} \mathrm{Ti}_{\mathrm{x}} \mathrm{O}_{2}$, as discussed above. Since most of implanted $\mathrm{Cr}$ and $\mathrm{Co}$ ions remain in $\mathrm{VO}_{2}$ films, they play as impurities in addition to the ion tracks. Impurities in $\mathrm{VO}_{2}$ can modify the band structure, contribute the charge carrier density of the conduction band, disturb the SPT, and interrupt the propagation of electrons. When $\mathrm{Cr}$ concentration increased in $\mathrm{VO}_{2}$, both lattice constants and structural disorder of $\mathrm{V}_{1-\mathrm{x}} \mathrm{Cr}_{\mathrm{x}} \mathrm{O}_{2}$ increased, while the $\mathrm{T}_{\mathrm{c}}$ value moved towards a higher temperature during both heating and cooling ${ }^{38,39}$. This is comparable to the $\mathrm{T}_{\mathrm{c}}$ behavior of $\mathrm{Cr}-\mathrm{VO}_{2}$ with the ion flux of $5 \times 10^{13}$ ions $/ \mathrm{cm}^{2}$.

The resistance and EXAFS measurements of the $\mathrm{Cr}$ - and $\mathrm{Co}-\mathrm{VO}_{2}$ films with different ion energies and fluxes show that the SPT always occurs before and after the MIT during heating and cooling, respectively. This indicates that a percolation effect is negligible in the systems and that an SPT, particularly the $\mathrm{V}$ atomic arrays, is an essential prerequisite for the MIT of $\mathrm{VO}_{2}$. This corresponds to that of the pristine $\mathrm{VO}_{2}$. A few defects in $\mathrm{VO}_{2}$ assist SPTs during heating and cooling whereas many defects interrupt SPTs. As a result, $\Delta \mathrm{T}_{\mathrm{c}}\left(\mathrm{T}_{\mathrm{cheating}}-\mathrm{T}_{\mathrm{c} \text { cooling }}\right)$ becomes small and large, as shown in Figs. 1 and 2, respectively. When the concentration of defects is larger than a critical value, the MIT of $\mathrm{VO}_{2}$ can be totally destoryed, as reported in previous studies ${ }^{61,62}$. The total amount of defects in a film due to implanted ions increases with increase in the flux and the penetration depth of the ions because the ions create linear tracks. When the energy of the implanted ions increases, the penetration depth is expanded, leading to the creation of more defects in the film. This scenario is consistent with the results of the Crand $\mathrm{Co}-\mathrm{VO}_{2}$ films with different energies and the same flux. For an ion flux of $10^{14} \mathrm{ions} / \mathrm{cm}^{2}$, MIT features from $\mathrm{Cr}-\mathrm{VO}_{2}$ are significantly reduced while an obvious MIT is observed from $\mathrm{Co}-\mathrm{VO}_{2}$. EXAFS reveals that $\mathrm{Cr}$ ions more seriously affect the $\mathrm{O}$ sites of $\mathrm{VO}_{2}$ than those of Co ions, as shown in Figs. 8 and 9. The penetration depths of the two ions on $\mathrm{VO}_{2}$ are roughly the same, as shown in the supplementary materials. Researchers observed that the $\mathrm{T}_{\mathrm{c}}$ values of $\mathrm{V}_{1-\mathrm{x}} \mathrm{Cr}_{\mathrm{x}} \mathrm{O}_{2}$ and $\mathrm{V}_{1-\mathrm{x}} \mathrm{Co}_{\mathrm{x}} \mathrm{VO}_{2}$ increased and decreased, respectively, relative to that of pristine $\mathrm{VO}_{2}{ }^{38,39,42}$, This implies that the contributions of $\mathrm{Cr}$ and $\mathrm{Co}$ ions on the MIT of $\mathrm{VO}_{2}$ are not the same, as they interrupt and assist the SPT, respectively. EXAFS measurements reveal that Cr ions more effectively destroy the crystalline structure of $\mathrm{VO}_{2}$ than Co ions do. The different effects of $\mathrm{Cr}$ and Co ions to $\mathrm{VO}_{2}$ could be attributed to the different radii and the different oxidation states of $\mathrm{Cr}^{3+}$ and $\mathrm{Co}^{2+}$ ions. This study indicates that the $\mathrm{T}_{\mathrm{c}}$ of $\mathrm{VO}_{2}$ can be increased or decreased by careful selection of a proper species of ions with different energies and fluxes.

\section{Conclusions}

For the $\mathrm{Cr}$ and $\mathrm{Co}$ ion fluxes $\leq 10^{14}$ ions $/ \mathrm{cm}^{2}$, both $\mathrm{Cr}$ - and $\mathrm{Co}-\mathrm{VO}_{2}$ show sharp MIT features near $\mathrm{T}_{\mathrm{c}}$. The $\mathrm{T}_{\mathrm{c}}$ of both the $\mathrm{Cr}$ - and $\mathrm{Co}-\mathrm{VO}_{2}$ films with a low ion flux is lower than that before ion implantation, while it shifts toward a higher temperature for a high ion flux. This indicates that the $\mathrm{T}_{\mathrm{c}}$ of $\mathrm{VO}_{2}$ can be engineered by properly 
selecting the flux, energy, and species of ion beam. Both Cr and Co ions create a substantial amount of structural disorder and distortion in $\mathrm{VO}_{2}$. Based on resistance and EXAFS measurements, model calculations suggest that a sharp and abrupt MIT and SPT can occur in $\mathrm{VO}_{2}$ unless more than $5 \%$ of the $\mathrm{V}$ sites are disturbed by impurities. Temperature-dependent XANES from $\mathrm{Cr}-\mathrm{VO}_{2}$ at the $\mathrm{V} \mathrm{K}$ edge showed that the pre-edge peak alone cannot fully describe either the MIT or the SPT. Temperature-dependent resistance and EXAFS measurements reveal that crystal field splitting in the $\mathrm{VO}_{6}$ octahedron of $\mathrm{VO}_{2}$ does not play a critical role in the MIT. These study results suggest that an SPT of the $\mathrm{V}$ atomic arrays and the interaction of $\mathrm{V} 3 \mathrm{~d}^{1}$ electrons are the necessary conditions for the MIT of $\mathrm{VO}_{2}$, supporting both the structural-driven-Peierls and Mott-Hubbard models. This study also shows that ion-implantation techniques can be widely used to engineer the $\mathrm{T}_{\mathrm{c}}$ and the MIT of $\mathrm{VO}_{2}$, and particularly of $\mathrm{VO}_{2}$ nanostructures, without degrading the sharpness of the MIT features ${ }^{23}$.

\section{Methods}

Synthesis of $\mathrm{VO}_{2}$ films. The $b$-oriented $\mathrm{VO}_{2}$ films were fabricated on $\alpha-\mathrm{Al}_{2} \mathrm{O}_{3}(0001)$ substrates using direct current (DC)-sputtering deposition from a vanadium target with a purity of $99.95 \%$. The base vacuum of the growth chamber was $10^{-6}$ Torr and the pressure was kept at $10^{-3}$ Torr during the deposition. Ar gas was used as the plasma and the substrate temperature was maintained at $\sim 500^{\circ} \mathrm{C}$. After deposition, the films were annealed at $500{ }^{\circ} \mathrm{C}$ for $30 \mathrm{~min}$ with a mixture gas flow of $\mathrm{Ar}: \mathrm{O}_{2}=300: 1$. More details of $\mathrm{VO}_{2}$ film fabrication can be found elsewhere in the literatures ${ }^{7,36}$.

$\mathrm{Cr}$ and $\mathrm{Co}$ ion implantation on $\mathrm{VO}_{2}$ films. $\mathrm{Cr}$ and Co ions with an energy of 30-100 keV and a flux of $10^{12}-10^{14}$ ions $/ \mathrm{cm}^{2}$ vertically bombarded the $\mathrm{VO}_{2}$ films at room temperature in a vacuum at the Korean MultiPurpose Accelerator Complex (KOMAC).

In-situ XAFS measurements. Temperature-dependent XAFS measurements were conducted from $\mathrm{Cr}-\mathrm{VO}_{2}$ and $\mathrm{Co}-\mathrm{VO}_{2}$ films and a pristine $\mathrm{VO}_{2}$ film as a counterpart at the $\mathrm{V} \mathrm{K}$ edge $(5465 \mathrm{eV})$. XAFS measurements were performed with a fluorescence mode using a $\mathrm{Si}(111)$ double-crystal monochromator at beamline $8 \mathrm{C}$ of the Pohang Light Source (PLS) and beamline 20-BM of the Advanced Photon Source (APS). The XAFS data were taken with an unpolarized geometry where the angle between the film surface and the incident X-ray beam was fixed at 45 degrees. During in-situ temperature-dependent XAFS measurements, the DC electrical resistance was simultaneously measured from the same specimens ${ }^{7,33}$. A thermocouple was directly contacted to the surface of $\mathrm{VO}_{2}$ film to accurately measure the true temperature of the film in real time. The resistance and the temperature were recorded after the temperature at each set temperature was stabilized. The temperature was monitored and controlled within \pm 0.1 degree during the XAFS scans and the resistance measurements. Each XAFS scan took approximately $15 \mathrm{~min}$.

DC resistance measurements. Two-probe DC-resistance measurements were performed from pristine, $\mathrm{Cr}-\mathrm{VO}_{2}$, and $\mathrm{Co}-\mathrm{VO}_{2}$ films before ion-implanted at the applied voltage of $0.5 \mathrm{~V}$ using a Keithley 2400 SourceMeter ${ }^{7,36}$. After the ions were implanted, the resistance measurements were simultaneously performed with in-situ XAFS measurements.

Received: 25 September 2020; Accepted: 18 January 2021

Published online: 04 February 2021

\section{References}

1. Morine, F. J. Oxides which show a metal-to-insulator transition at the Neel temperature. Phys. Rev. Lett. 3, 34 (1959).

2. Goodenough, J. B. The two components of the crystallographic transition in VO. J. Solid State Chem. 3, 490 (1971).

3. Eyert, V. The metal-insulator transitions of $\mathrm{VO}_{2}$ : a band theoretical approach, Ann. Phys. (Leipzig) 11, 650 (2002).

4. Yang, Z. et al. Oxide electronics utilizing ultrafast metal-insulator transitions. Ann. Rev. Mater. Res. 41, 337 (2011).

5. Qazilbash, M. M. et al. Basov, Mott transition in $\mathrm{VO}_{2}$ revealed by infrared spectroscopy and nano-imaging. Science 318, 1750 (2007).

6. Shao, Z. et al. Recent progress in the phase-transition mechanism and modulation of vanadium dioxide materials. NPG Asia Mater. 10, 581 (2018).

7. Hwang, I.-H. et al. The influence of structural disorder and phonon on metal-to-insulator transition of VO $\mathrm{VO}_{2}$ Sci. Rep. 7,14802 (2018).

8. Kim, H.-T. et al. Mechanism and observation of Mott transition in $\mathrm{VO}_{2}$-based two- and three-terminal devices. New J. Phys. 6, 52 (2004).

9. Shukla, N. et al. A steep-slope transistor based on abrupt electronic phase transition. Nat. Commun. 6, 7812 (2015).

10. Zhou, J. et al. $\mathrm{VO}_{2}$ thermochromic smart window for energy savings and generation. Sci. Rep. 3, 3029 (2013).

11. Liang, S. et al. One-step hydrothermal synthesis of $\mathrm{W}$-doped $\mathrm{VO}_{2}(\mathrm{M})$ nanorods with a tunable phase-transition temperature for infrared smart windows. ACS Omega 1, 1139 (2016).

12. Strelcov, E. et al. Gas sensor based on metal-insulator transition in $\mathrm{VO}_{2}$ nanowire thermistor. Nano Lett. 9, 2322 (2009).

13. Reddy, C. V. S. et al. Synthesis of $\mathrm{VO}_{2}$ (B) nanorods for Li battery application. Curr. Appl. Phys. 9, 1195 (2009).

14. Mjejri, I. et al. Vanadium oxides nanostructures: Hydrothermal synthesis and electrochemical properties. Ceram. Int. 40, 1387 (2014).

15. Cilento, F. et al. Ultrafast insulator-to-metal phase transition as a switch to measure the spectrogram of a supercontinuum light pulse. Appl. Phys. Lett. 96, 021102 (2010).

16. Liu, M. et al. Terahertz-field-induced insulator-to-metal transition in vanadium dioxide metamaterial. Nature 487, 345 (2012).

17. Tan, X. et al. Unraveling metal-insulator transition mechanism of $\mathrm{VO}_{2}$ triggered by tungsten doping. Sci. Rep. 2, 466 (2012).

18. Chen, L. et al. Atomic and electronic structures of charge-doping $\mathrm{VO}_{2}$ : first-principles calculations. RSC Adv. 10, 18543 (2020). 
19. Matsuda, Y. H. et al. Magnetic-field-induced insulator-metal transition in W-doped $\mathrm{VO}_{2}$ at 500 T. Nat. Commun. 11, 3591 (2020).

20. Xing He, X. et al. Photoinduced strain release and phase transition dynamics of solid-supported ultrathin vanadium dioxide. Sci. Rep. 7, 10045 (2017).

21. Jeong, J. et al. Suppression of metal-insulator transition in $\mathrm{VO}_{2}$ by electric field-induced oxygen vacancy formation. Science 339, $1402(2013)$.

22. J. Cao, J. et al. Strain engineering and one-dimensional organization of metal-insulator domains in single-crystal vanadium dioxide beams, Nat. Nanotech. 4, 732 (2009).

23. Hongwei, L. et al. Size effects on metal-insulator phase transition in individual vanadium dioxide nanowires. Opt. Express 22, 30748 (2014).

24. Wentzcovitch, R. M. et al. $\mathrm{VO}_{2}$ : peierls or Mott-Hubbard? A view from band theory. Phys. Rev. Lett. 72, 3389 (1994).

25. Yao, T. et al. Understanding the nature of the kinetic process in a $\mathrm{VO}_{2}$ metal-insulator transition. Phys. Rev. Lett. 105, 226405 (2010).

26. Kim, H.-T. et al. Monoclinic and correlated metal phase in $\mathrm{VO}_{2}$ as evidence of the Mott transition: coherent phonon analysis. Phys. Rev. Lett. 97, 266401 (2006).

27. Xu, S. et al. Unified band-theoretic description of structural, electronic, and magnetic properties of vanadium dioxide phases. Phys. Rev. B 95, 125105 (2017).

28. Brito, W. H. et al. Metal-insulator transition in $\mathrm{VO}_{2}$ : a DFT + DMFT perspective. Phys. Rev. Lett. 117, 056402 (2016).

29. Li, Z. et al. Imaging metal-like monoclinic phase stabilized by surface coordination effect in vanadium dioxide nanobeam. Nat. Commun. 8, 15561 (2017).

30. Biermann, S. et al. Dynamical singlets and correlation-assisted Peierls transition in $\mathrm{VO}_{2}$. Phys. Rev. Lett. 94, 026404 (2005).

31. Mun, B. S. et al. Nonpercolative metal-insulator transition in $\mathrm{VO}_{2}$ single crystals. Phys. Rev. B 84, 113109 (2011).

32. Muraoka, Y. et al. Metal-insulator transition of $\mathrm{VO}_{2}$ thin films grown on $\mathrm{TiO}_{2}(001)$ and (110) substrates. Appl. Phys. Lett. 80, 583 (2002).

33. Jin, Z. et al. Structural and electrical properties of $\mathrm{VO}_{2} / \mathrm{ZnO}$ nanostructures. Curr. Appl. Phys. 18, 353 (2018).

34. Wong, F. J. et al. Epitaxial variants of $\mathrm{VO}_{2}$ thin films on complex oxide single crystal substrates with $3 m$ surface symmetry. J. Crystal Growth 364, 74 (2013)

35. Hwang, I.-H. et al. Anomalous structural disorder and distortion in metal-to-insulator-transition $\mathrm{Ti}_{2} \mathrm{O}_{3}$. J. Appl. Phys. 119, 014905 (2016).

36. Jin, Z. et al. Synthesis and temperature-dependent local structural and electrical properties of $\mathrm{VO}_{2}$ films. Curr. Appl. Phys. 16, 183 (2016).

37. Marezio, M. et al. Structural aspects of the metal-insulator transitions in Cr-Doped VO . Phys. Rev. B 5, 2541 (1972).

38. Brown, B. L. et al. Electrical and optical characterization of the metal-insulator transition temperature in Cr-doped $\mathrm{VO}_{2}$ thin films. J. Appl. Phys. 113, 173704 (2013).

39. Zou, Z. et al. Thermochromic, threshold switching, and optical properties of $\mathrm{Cr}$ doped $\mathrm{VO}_{2}$ thin films. J. Alloy Compd. 806, 310 (2019).

40. Marini, C. et al. Optical properties of $\mathrm{V}_{1-x} \mathrm{Cr}_{\mathrm{x}} \mathrm{O}_{2}$ compounds under high pressure. Phys. Rev. B 77, 235111 (2008).

41. Wu, Y. et al. Depressed transition temperature of $\mathrm{W}_{\mathrm{x}} \mathrm{V}_{1-\mathrm{x}} \mathrm{O}_{2}$ : mechanistic insights from the X-ray absorption fine structure (XAFS) spectroscopy. Phys. Chem. Chem. Phys. 16, 17705 (2014).

42. Lu, C. et al. Terahertz transmittance of cobalt-doped $\mathrm{VO}_{2}$ thin film: Investigated by terahertz spectroscopy and effective medium theory. IEEE Trans. THz. Sci. Tech. 9, 177 (2019).

43. Holman, K. L. et al. Insulator to correlated metal transition in $\mathrm{V}_{1-\mathrm{x}} \mathrm{Mo}_{\mathrm{x}} \mathrm{O}_{2}$. Phys. Rev. B 79, 245114 (2009).

44. $\mathrm{Wu}$, Y. et al. Decoupling the lattice distortion and charge doping effects on the phase transition behavior of $\mathrm{VO}_{2}$ by titanium $\left(\mathrm{Ti}^{4+}\right)$ doping. Sci. Rep. 5, 9328 (2015).

45. Biersack, J. P. et al. A Monte Carlo computer program for the transport of energetic ions in amorphous targets. Nucl. Instrum. Methods 174, 257 (1980).

46. Park, C.-I. et al. Linear defects and electrical properties of ZnO nanorods. Appl. Phys. Lett. 112, 253101 (2018).

47. Fu, D. et al. Comprehensive study of the metal-insulator transition in pulsed laser deposited epitaxial $\mathrm{VO}_{2}$ thin films. J. Appl. Phys. 113, 043707 (2013).

48. Lee, S. et al. Electronic structure and insulating gap in epitaxial $\mathrm{VO}_{2}$ polymorphs. APL Mater. 3, 126109 (2015)

49. Moatti, A. et al. Electrical transition in isostructural $\mathrm{VO}_{2}$ thin-film heterostructures. Sci. Rep. 9, 3009 (2019).

50. Sayers, D. E. et al. New technique for investigating noncrystalline structures: Fourier analysis of the extended X-ray-absorption fine structure. Phys. Rev. Lett. 27, 1204 (1971).

51. Rehr, J. J. et al. Theoretical approaches to X-ray absorption fine structure. Rev. Mod. Phys. 72, 621 (2000).

52. Han, S.-W. X-ray absorption fine structure and nanostructures. Int. J. Nanotechnol. 3, 396 (2006)

53. Newville, M. IFEFFIT: interactive XAFS analysis and FEFF fitting. J. Synchrotron Radiat. 8, 322 (2001).

54. Han, S.-W. et al. Local structure in the stripe phase of $\mathrm{La}_{1.6-\mathrm{x}} \mathrm{Sr}_{\mathrm{x}} \mathrm{Nd}_{0.4} \mathrm{CuO}_{4}$, Phys. Rev. B 66, 094101 (2002).

55. Lu, Y.-R. et al. Atomic and electronic aspects of the coloration mechanism of gasochromic Pt/Mo-modified $\mathrm{V}_{2} \mathrm{O}_{5}$ smart films: an in situ X-ray spectroscopic study. Phys. Chem. Chem. Phys. 18, 5203 (2016).

56. Seo, S.-Y. et al. X-ray absorption fine structure study of cobalt ion distribution in ferromagnetic $\mathrm{Zn}_{1-\mathrm{x}} \mathrm{Co}_{\mathrm{x}} \mathrm{O}$ films. J. Phys.: Condens. Matter. 25, 256005 (2013).

57. Laverock, J. et al. Observation of weakened V-V dimers in the monoclinic metallic phase of strained $\mathrm{VO}_{2}$. Phys. Rev. Lett. 121, 256403 (2018).

58. Holz, A. et al. Theory of discontinuos metal-insulator and spin-dimerization transition in $\mathrm{VO}_{2}$. J. Magn. Magn. Mater. 7, 329 (1978).

59. Zhang, R. et al. Understanding of metal-insulator transition in $\mathrm{VO}_{2}$ based on experimental and theoretical investigations of magnetic features. Sci Rep. 8, 17093 (2018).

60. Wall, S. et al. Ultrafast disordering of vanadium dimers in photoexcited $\mathrm{VO}_{2}$. Science 362, 572 (2018).

61. Hofsäss, H. et al. Tuning the conductivity of vanadium dioxide films on silicon by swift heavy ion irradiation. AIP Adv. 1, 032168 (2011).

62. Khan, G. R. et al. Augmentation of thermoelectric performance of $\mathrm{VO}_{2}$ thin films irradiated by $200 \mathrm{MeV} \mathrm{Ag}{ }^{9+}$-ions. Radiat. Phys. Chem. 123, 55 (2016).

\section{Acknowledgements}

The work was conducted under the auspices of the Basic Science Research Program through the National Research Foundation of Korea government grant funded by the Ministry of Education (Nos. 2017K1A3A7A09016390, 2020K1A3A7A09080403) and the research funds of Jeonbuk National University in 2019. The Cr- and Co-ion implantation was performed at KOMAC in Korea and the XAFS data were collected at the beamline 8C of PLS in Korea and beamline 20-BM of APS in USA. This research used resources of APS, an Office of Science User Facility operated for the U.S. Department of Energy (DOE) Office of Science by Argonne National Laboratory, 
and was supported by the U.S. DOE under Contract No. DE-AC02-06CH11357, and the Canadian Light Source and its funding partners.

\section{Author contributions}

I.-H.H., C.-I.P., C.-J.S., and S.-W.H. performed in-situ XAFS and electrical resistance measurements. S.Y. and C.-I.P. performed $\mathrm{Cr}$ and $\mathrm{Co}$ ion-implantation experiments on $\mathrm{VO}_{2}$ and examined the distributions of implanted $\mathrm{Cr}$ and $\mathrm{Co}$ ions on $\mathrm{VO}_{2}$. I.-H.H. synthesized $\mathrm{VO}_{2}$ films using the DC sputtering deposition, performed DCelectrical resistance measurements, and analyzed the data of the resistance and the XAFS. S.-W.H. designed this study and wrote the paper.

\section{Competing interests}

The authors declare no competing interests.

\section{Additional information}

Supplementary Information The online version contains supplementary material available at https://doi. org/10.1038/s41598-021-82588-4.

Correspondence and requests for materials should be addressed to S.-W.H.

Reprints and permissions information is available at www.nature.com/reprints.

Publisher's note Springer Nature remains neutral with regard to jurisdictional claims in published maps and institutional affiliations.

(c) (i) Open Access This article is licensed under a Creative Commons Attribution 4.0 International License, which permits use, sharing, adaptation, distribution and reproduction in any medium or format, as long as you give appropriate credit to the original author(s) and the source, provide a link to the Creative Commons licence, and indicate if changes were made. The images or other third party material in this article are included in the article's Creative Commons licence, unless indicated otherwise in a credit line to the material. If material is not included in the article's Creative Commons licence and your intended use is not permitted by statutory regulation or exceeds the permitted use, you will need to obtain permission directly from the copyright holder. To view a copy of this licence, visit http://creativecommons.org/licenses/by/4.0/.

(C) The Author(s) 2021 